Article

\title{
An Enhanced Carbon Capture and Storage Process (e-CCS) Applied to Shallow Reservoirs Using Nanofluids Based on Nitrogen-Rich Carbon Nanospheres
}

\author{
Elizabeth Rodriguez Acevedo ${ }^{1,2, *}$, Farid B. Cortés ${ }^{1, *}$, Camilo A. Franco ${ }^{1}(\mathbb{D}$, \\ Francisco Carrasco-Marín ${ }^{2}\left(\mathbb{D}\right.$, Agustín F. Pérez-Cadenas ${ }^{2} \mathbb{D}$, Vanessa Fierro $^{3} \mathbb{D}$, Alain Celzard ${ }^{3}$ (D), \\ Sébastien Schaefer ${ }^{3}$ and Agustin Cardona Molina ${ }^{4}$ \\ 1 Grupo de Investigación en Fenómenos de Superficie-Michael Polanyi, Facultad de Minas, \\ Universidad Nacional de Colombia-Sede Medellín, Medellín 050034, Colombia \\ 2 Research Group in Carbon Materials, Faculty of Sciences, University of Granada, Granada 18071, Spain \\ 3 Bio-Sourced Materials Research Group, Institut Jean Lamour, UMR CNRS-Université de Lorraine, \\ Epinal 88051, France \\ 4 Grupo de Investigación en Yacimientos de Hidrocarburos, Facultad de Minas, \\ Universidad Nacional de Colombia-Sede Medellin, Medellín 050034, Colombia \\ * Correspondence: ecrodrig@unal.edu.co (E.R.A.); fbcortes@unal.edu.co (F.B.C.); \\ Tel.: +57-301-3995162 (E.R.A.); +57-318-3474625 (F.B.C.)
}

Received: 1 June 2019; Accepted: 22 June 2019; Published: 28 June 2019

\begin{abstract}
The implementation of carbon capture and storage process (CCS) has been unsuccessful to date, mainly due to the technical issues and high costs associated with two main stages: (1) $\mathrm{CO}_{2}$ separation from flue gas and (2) $\mathrm{CO}_{2}$ injection in deep geological deposits, more than $300 \mathrm{~m}$, where $\mathrm{CO}_{2}$ is in supercritical conditions. This study proposes, for the first time, an enhanced CCS process (e-CCS), in which the stage of $\mathrm{CO}_{2}$ separation is removed and the flue gas is injected directly in shallow reservoirs located at less than $300 \mathrm{~m}$, where the adsorptive phenomena control $\mathrm{CO}_{2}$ storage. Nitrogen-rich carbon nanospheres were used as modifying agents of the reservoir porous texture to improve both the $\mathrm{CO}_{2}$ adsorption capacity and selectivity. For this purpose, sandstone was impregnated with a nanofluid and $\mathrm{CO}_{2}$ adsorption was evaluated at different pressures (atmospheric pressure and from $3 \times 10^{-3} \mathrm{MPa}$ to $\left.3.0 \mathrm{MPa}\right)$ and temperatures $\left(0,25\right.$, and $\left.50{ }^{\circ} \mathrm{C}\right)$. As a main result, a mass fraction of only $20 \%$ of nanomaterials increased both the surface area and the molecular interactions, so that the increase of adsorption capacity at shallow reservoir conditions $\left(50{ }^{\circ} \mathrm{C}\right.$ and $3.0 \mathrm{MPa}$ ) was more than 677 times (from 0.00125 to $0.9 \mathrm{mmol} \mathrm{g}^{-1}$ ).
\end{abstract}

Keywords: adsorption; carbon capture and storage process (CCS); carbon dioxide; nanofluids; nanoparticles and shallow reservoirs

\section{Introduction}

In recent decades, climate changes have generated negative consequences such as loss of sea ice, accelerated rise of sea level, extinction of some species, drought and population displacements, among others [1-5]. These changes are caused by human activities, mainly through the release of greenhouse gases [4-7]. The anthropogenic emissions of carbon dioxide, $\mathrm{CO}_{2}$, from fossil fuel combustion and industrial processes contributed to about $78 \%$ of the total greenhouse gases emissions [8-10], and $\mathrm{CO}_{2}$ emissions have increased by $46 \%$ since pre-industrial times [11,12]. The huge $\mathrm{CO}_{2}$ daily emissions and their growth increase its responsibility on global climate change [12-16]. Raw material industries such 
as chemical, petrochemical, iron, steel, cement, and others, contribute with the most to $\mathrm{CO}_{2}$ emissions worldwide $[17,18]$. The advantage of $\mathrm{CO}_{2}$ industrial emissions is that they are fixed sources so that they can be controlled in-situ. A typical flue gas from coal-fired boilers may contain $12-14 \mathrm{vol} \% \mathrm{CO}_{2}$, 8-10 vol $\% \mathrm{H}_{2} \mathrm{O}, 3-5 \mathrm{vol} \% \mathrm{O}_{2}$, and $72-77 \% \mathrm{~N}_{2}$ [19-21]. The method most frequently used at industrial levels for $\mathrm{CO}_{2}$ capture is absorption. However, this method has significant limitations related to solvent regeneration, composition of flue gas, $\mathrm{CO}_{2}$ concentration, corrosion, high-energy consumption, etc. $[15,16,18,22]$. Other methods are cryogenic distillation, membranes, and adsorption by porous solids. Hence, the current methods are not enough, and $\mathrm{CO}_{2}$ emissions continue to increase $[12,17,23]$. For this reason, it is necessary to broaden the portfolio of methods to reduce $\mathrm{CO}_{2}$ emissions significantly in the years to come.

The Intergovernmental Panel on Climate Change (IPCC) promotes the carbon capture and storage process (CCS), which allows the geological storage of $\mathrm{CO}_{2}$ emitted by the industry over the long term $[10,18,24]$. The CCS process might decrease $\mathrm{CO}_{2}$ emissions by approximately $22 \%$ in $2035[25,26]$. The CCS process has three main stages: 1) $\mathrm{CO}_{2}$ capture and separation from flue gas, 2) $\mathrm{CO}_{2}$ transport to the storage site, and 3) $\mathrm{CO}_{2}$ injection into deep geological storage sites, 300 to $4000 \mathrm{~m}$, and $800 \mathrm{~m}$ on average [22]. In this case, $\mathrm{CO}_{2}$ capture and storage are mainly due to the inter-particle volume filling. Figure 1a presents a scheme of the CCS process.

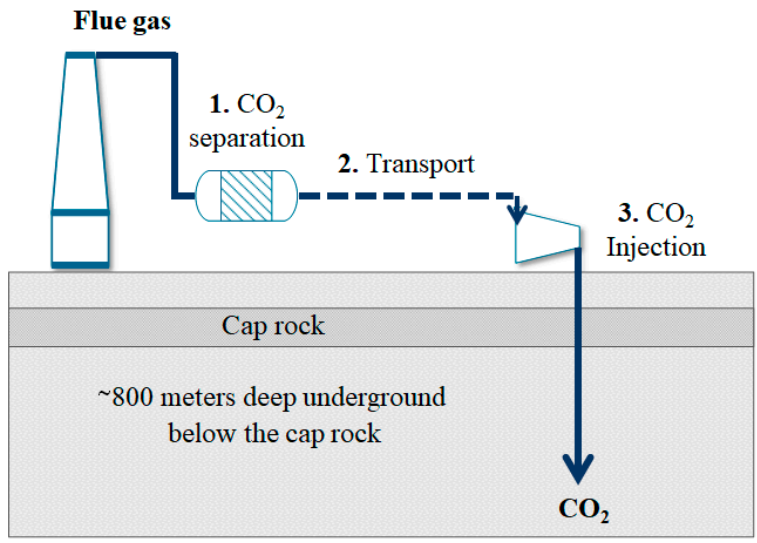

(a)

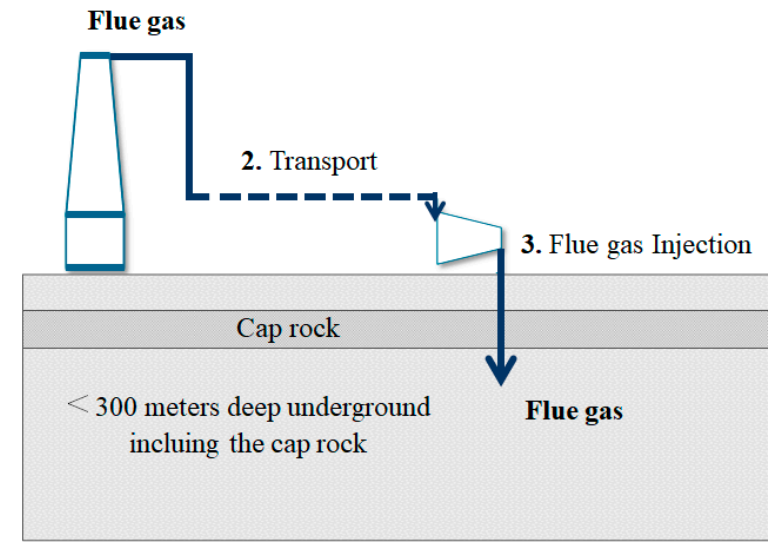

(b)

Figure 1. Configurations of the carbon capture and storage (CCS) process: (a) conventional CCS process; (b) proposed enhanced CSS (e-CCS) process.

It is estimated that $50 \%$ of the CCS projects use sandstone deposits for storage because they have technical advantages and high availability [24]. Oil and gas deposits are indeed mostly composed of sandstone, which provides a natural storage structure, with porous texture and upper and lateral seals that allow long-term storage. Carbon capture and storage have been coupled with other processes such as enhanced oil recovery (EOR) or enhanced coal bed methane production (ECBM) [24].

However, its in situ industrial implementation has been unsuccessful mainly due to the technical and economic costs associated with the separation and storage stages. In general, the cost of $\mathrm{CO}_{2}$ capture is $70-80 \%$ of the total CCS costs [26-28]. For this reason, the current research focuses mainly on increasing the $\mathrm{CO}_{2} /$ flue gas separation capacity in order to decrease energy consumption, or on the use of waste energy, among others. This study proposes an alternative to minimize the technical and economic cost for the viability of the CCS process. Figure $1 \mathrm{~b}$ presents the configuration of an enhanced CCS process (e-CCS), in which the stage of $\mathrm{CO}_{2}$ capture/separation is removed, and the flue gas is injected directly into shallow deposits, at depths less than $300 \mathrm{~m}$. In this case, $\mathrm{CO}_{2}$ remains in a gaseous state, and the adsorption process controls the capture and storage. The density of $\mathrm{CO}_{2}$ is very different in gaseous or supercritical conditions, which affects the amount of $\mathrm{CO}_{2}$ stored in the e-CCS process. For this, it is necessary to add a modifying agent to the surface of the porous medium in order to improve the adsorption capacity and the $\mathrm{CO}_{2}$ selectivity, since the adsorption (capture/storage) 
process is done underground. In addition, the modifying agent should not affect the naturally porous structure of the deposit to avoid operational problems.

Nanostructured materials constitute a vast and active field of research in various areas, due to their intrinsic characteristics that can be adjusted depending on the foreseen application, such as porosity, structure, molecular affinity, high surface-area-to-volume ratio, high surface activity, dispersion capacity, and optical and electronic properties, etc. [29]. Nanoparticles have been used to increase the recovery of oil and gas by modifying the physicochemical properties of the reservoirs [30,31], and to modify reservoirs' wettability, asphaltenes adsorption, catalysis and stabilization of fines in reservoirs, among others [30,32-35]. The obtained results demonstrate their effectiveness in achieving this objective without obstruction of the porous media. In this way, nanospheres can be an option for the modification of the surface in shallow reservoirs for the e-CCS process. Although nanoparticles have been evaluated for the conventional CCS process in the form of a nanofluid used to improve $\mathrm{CO}_{2}$ transport in saline aquifers [36], they have not been used for rock modification and improvement of the $\mathrm{CO}_{2}$ storage capacity, such as in the case of the proposed e-CCS process, to the best of our knowledge.

Many adsorbents for $\mathrm{CO}_{2}$ capture have been reported, such as carbon materials, metal organic frameworks, zeolites, alkali metal carbonates, etc. [16,37-39], but not widely at the nanoscale level, with spherical structures allowing their application in geological deposits. Many carbon nanostructures have been evaluated for $\mathrm{CO}_{2}$ capture, among them nanofibers, nanosheets, and nanotubes, leading to adsorption capacities ranging from 0.26 to $4.15 \mathrm{mmol} \mathrm{g}^{-1}$ under atmospheric conditions [16,40-45]. However, these materials are not applicable to reservoirs due to their structure and dimensions that might affect the nature of the reservoir's porous structure. Carbon nanospheres, thus, appear to be the best choice for the e-CCS process. Wang et al. [16] analyzed different adsorbents and concluded that carbon materials are one of the best options, mainly due to their low cost, high surface area, adjustable porous texture, and easy surface functionalization [16,37-39]. Chen et al. [46] reported hollow carbon nanospheres with a $\mathrm{CO}_{2}$ adsorption capacity of $3.65 \mathrm{mmol} \mathrm{g}^{-1}$ under atmospheric conditions [46], which is similar to what was reported for other nanomaterials such as carbon fibers, carbon nanosheets, carbon nanotubes, metal organic frameworks, zeolites, alkali metal carbonates, etc [16,37-39]. For $\mathrm{CO}_{2}$ adsorption applications, a high surface area is essential as well as basic functionalities, due to the acidic character of the $\mathrm{CO}_{2}$ molecule. Therefore, high nitrogen content in the adsorbent allows obtaining a basic nature and enhances the adsorption capacity and selectivity. Some authors suggested increasing the nitrogen content by impregnating the materials with amines like the materials commonly called supported amine material, which consist of a porous support onto which an amine is attached or immobilized [16,37-39,47]. However, treatment with amines can obstruct the microporosity of the nanomaterial, thereby decreasing its adsorption capacity and increasing its final cost. Also, in some cases, like samples containing grafted primary and tertiary monoamines, the material could be deactivated in the presence of oxygen-containing gases [47]. Thus, it is desirable to incorporate nitrogen groups during the material's synthesis. Hence, amine or amino acid functional groups are grafted on the surface of the support during the synthesis process instead of physically dispersed in the pores after synthesizing the support material [48].

The main objective of this manuscript was, therefore, to experimentally study the possibility of improving the CCS process through nanotechnology. For this, carbon nanospheres with different structures were synthesized, characterized, and used to impregnate sandstone using different mass ratios of nanoparticles to sandstone. The $\mathrm{CO}_{2}$ adsorption process, as well as its thermodynamic parameters, were evaluated under atmospheric and high-pressure conditions.

\section{Materials and Methods}

Two different carbon nanostructures were synthesized using either a sol-gel method or a solvothermal method. The synthesized nanostructures were labeled and synthesized as follows:

(1) CN.LYS: Carbon nanospheres obtained from a sol-gel method, using resorcinol/formaldehyde as carbon precursor and L-lysine as catalyst and nitrogen precursor. 
(2) CN.MEL: Carbon nanostructures obtained from a solvothermal method, using carbon tetrachloride as carbon precursor and melamine as nitrogen precursor.

Both CN.LYS and CN.MEL were characterized in order to select the best material, considering the nanometer size, adsorption capacity, lower technical and economic cost, and method of synthesis. Ottawa sandstone was used as porous medium and was impregnated with the best nanomaterial at different percentages. The performances of the materials were evaluated by $\mathrm{CO}_{2}$ adsorption at atmospheric pressure and at $0{ }^{\circ} \mathrm{C}$, and by varying pressure and temperature conditions. The detailed procedures are presented below.

\subsection{Materials and Reagents}

For the synthesis processes, the following reagents were used, all from Sigma-Adrich, St. Louis, USA: carbon tetrachloride ( $\geq 99.9 \%)$, melamine $(99 \%)$, formaldehyde $(37 \%)$, resorcinol $(\geq 99 \%)$, L-lysine $(>98 \%)$, sodium dodecylbenzene sulfonate (SDBS), and deionized water.

For cleaning, drying, and carbonization, the following chemicals were used, all from Sigma-Adrich again except $\mathrm{N}_{2}$ : acetone (99.9\%), ethanol (99.5\%), hydrochloric acid $(37 \%$,), tert-butanol $(\geq 99.5 \%)$, and $\mathrm{N}_{2}$ (high purity, grade 5.0). Clean Ottawa sandstone and sandstone from a real reservoir were used as porous media. The real sandstone was obtained from a Colombian oil field, which allows evaluating the real rock that might be used to implement the e-CCS process in depleted oil fields.

\subsection{Synthesis of Nanomaterials}

\subsubsection{CN.LYS Synthesis}

The process was adapted from Yong-Rong et al. [48], changing the lysine concentration, the reaction time and the resorcinol/water molar ratio. A solution (S1) of resorcinol/formaldehyde in a 1:2 molar ratio, and deionized water was stirred at $25^{\circ} \mathrm{C}$ for $1 \mathrm{~h}$. In parallel, a solution (S2) of L-lysine and deionized water was stirred at $60^{\circ} \mathrm{C}$ for $1 \mathrm{~h}$. The molar ratio of resorcinol/L-lysine was 1:0.16. Subsequently, the solutions S1 and S2 were mixed at $60^{\circ} \mathrm{C}$ for $1 \mathrm{~h}$ to obtain the solution S3. The latter was maintained at $25{ }^{\circ} \mathrm{C}$ for $20 \mathrm{~h}$ to benefit from the natural precipitation of the nanomaterial. Finally, the obtained polymer was dried at $120^{\circ} \mathrm{C}$ for $12 \mathrm{~h}$ and carbonized under $\mathrm{N}_{2}$ flowing at $60 \mathrm{~mL} \mathrm{~min}^{-1}$, using a tubular furnace. The temperature was increased up to $800{ }^{\circ} \mathrm{C}$ at a rate of $1{ }^{\circ} \mathrm{C} \mathrm{min}-1$, and the final temperature was held for $5 \mathrm{~h}$. The employed molar ratios of resorcinol/water (for S1) were 1:2778 (without dilution), 1:5556 (dilution 1), and 1:11112 (dilution 2) for obtaining the CN.LYS1, CN.LYS2, and CN.LYS3 materials, respectively. Different molar ratios of resorcinol to water were used to reduce particle size.

\subsubsection{CN.MEL Synthesis}

The CN.MEL synthesis was adapted from Bai et al. [49] by dissolving $2 \mathrm{~g}$ of melamine in $120 \mathrm{~mL}$ of carbon tetrachloride [49]. This solution was put in a stainless-steel autoclave (Parr Instrument, Illinois, USA) with a capacity of $200 \mathrm{~mL}$ and introduced into an oven (Thermo Fisher Scientific, Massachusetts, USA) at $250{ }^{\circ} \mathrm{C}$ for $24 \mathrm{~h}$. The synthesis was carried out under auto-generated pressure. Subsequently, the carbonaceous material that formed was separated from the solution, and was cleaned with acetone, ethanol, and finally $0.1 \mathrm{~mol} \mathrm{~L}^{-1} \mathrm{HCl}$. A mixture of nanospheres and fibers (formed by aggregation of nanospheres) was obtained (Gel.MEL1).

To obtain N-rich carbon spheres, the Gel.MEL1 was coated with a mixture of resorcinol and formaldehyde in a 1:2 molar ratio. Initially, the gel was stirred with sodium dodecylbenzene sulfonate (SDBS) at $25^{\circ} \mathrm{C}$ for $18 \mathrm{~h}$ to promote the subsequent interaction with resorcinol/formaldehyde. After $18 \mathrm{~h}$, the gel/SDBS was mixed with resorcinol/formaldehyde (in proportions of $0.37 \mathrm{~g}$ of nanoparticles per $1 \mathrm{~g}$ of resorcinol) and put in a stainless-steel autoclave at $130{ }^{\circ} \mathrm{C}$ for $24 \mathrm{~h}$. In order to maintain its porous texture, the gel was dried by freeze-drying. First, the material was impregnated with tert-butanol for three days. Then, the impregnated material was frozen at $-5^{\circ} \mathrm{C}$ and lyophilized for 
two days until the tert-butanol was entirely removed (Gel.MEL2). Finally, the lyophilized gel was carbonized under $\mathrm{N}_{2}$ flow $\left(60 \mathrm{~mL} \mathrm{~min}^{-1}\right)$ in a tubular furnace (Thermo Fisher Scientific, Massachusetts, USA). The temperature was increased at a heating rate of $1^{\circ} \mathrm{C} \min ^{-1}$ up to $700{ }^{\circ} \mathrm{C}$, and the latter temperature was held for $6 \mathrm{~h}$.

\subsubsection{Impregnation of Sandstones}

The sandstone was impregnated to decorate the rock surface with the nanoparticles and improve the surface area and molecular interactions. Ottawa sandstone (SS) was impregnated with CN.LYS2 at mass fractions of $0.01,0.1,1,5,10$, and $20 \%$ by immersion and soaking [50]. Initially, a nanofluid composed of nanoparticles and deionized water was sonicated at $40^{\circ} \mathrm{C}$ for $4 \mathrm{~h}$. Subsequently, the SS was introduced in the nanofluid at $60^{\circ} \mathrm{C}$ for either $6 \mathrm{~h}$ at $600 \mathrm{rpm}$ or for $24 \mathrm{~h}$ without stirring.

The latter method better mimics the reservoir conditions in which the porous medium might be impregnated. Finally, the impregnated material was dried at $110^{\circ} \mathrm{C}$ for $12 \mathrm{~h}$. The same procedure was followed for impregnating the sandstone from a real reservoir (RS) but using only a mass fraction of 10 and $20 \%$ of CN.LYS2 to RS and $24 \mathrm{~h}$ of soaking.

\subsection{Characterization of the Nanomaterials}

The following procedures allowed characterizing the physicochemical characteristics of the materials, essential for a good understanding of the results. For e-CCS application, nanoparticles must have a nanometer size, a spherical shape, a high surface area, and a high nitrogen content.

\subsubsection{Size and Structure of Nanomaterials}

Different techniques were used to evaluate the particle size distribution: scanning electron microscopy (SEM) was used to obtain the dry particle size, size distribution, and morphology of CN.MEL, whereas transmission electron microscopy (TEM) was used to analyze the dry particle size, size distribution, and surface characteristics of CN.LYS. The CN.LYS showed a different porous structure after dilutions, which was observed by $\mathrm{N}_{2}$ adsorption (at $-196{ }^{\circ} \mathrm{C}$ ). Further, TEM was used to characterize the structure after dilutions to analyze the causes of pore structure modification. Scanning electron microscopy analysis was also carried out to analyze the distribution of carbon nanoparticles on sandstone after impregnation. The observations were carried out by means of a JSM-7100 emission electron microscope (JEOL, Nieuw-Vennep, The Netherlands), a GEMINI-LEO1530 VP FE-SEM emission electron microscope (Carl Zeiss, Cambridge, UK), and a Tecnai F20 Super Twin TMP transmission electron microscope (FEI, Hillsboro, USA).

Dynamic light scattering (DLS) was carried out by means of a NanoPlus-3 zeta/nanoparticle analyzer (Micromeritics, Norcross, USA) at $25^{\circ} \mathrm{C}$ in a glass cell (capacity of $0.9 \mathrm{~mL}$ ), which was used to obtain the mean particle size of nanoparticles dispersed in a fluid, which hydrate and interact with each other. The mean particle size was calculated from the diffusional properties of the particle indicating the size of the hydrated and solvated particle. For this purpose, a nanoparticle solution, $10 \mathrm{mg} \mathrm{L}^{-1}$, was dispersed in water or ethanol and sonicated for $6 \mathrm{~h}$ before analysis. Particles suspended in a liquid have a Brownian motion due to the random collisions with solvent molecules. This motion causes the particles to diffuse through the medium. The diffusion coefficient, $D$, is inversely proportional to the particle size or hydrodynamic diameter, $d$, according to the Stokes-Einstein equation:

$$
\mathrm{D}=\frac{k_{B} T}{3 \pi \eta d}
$$

where, $k_{\mathrm{B}}$ is Boltzmann's constant, $T$ is the absolute temperature, and $\eta$ is the viscosity. 


\subsubsection{Porous Structure of Nanomaterials and Sandstone}

All materials were characterized by $\mathrm{N}_{2}$ and $\mathrm{CO}_{2}$ adsorption at $-196{ }^{\circ} \mathrm{C}$ and $0{ }^{\circ} \mathrm{C}$, respectively, using a 3-Flex manometric adsorption equipment (Micromeritics, Norcross, USA). The total adsorbed volume $\left(V_{0.95}\right)$ was taken as the physiosorbed volume of $\mathrm{N}_{2}$ at a relative pressure $P / P_{0}=0.95$. The Brunauer-Emmett-Teller (BET) model was applied to obtain the BET area $\left(A_{\mathrm{BET}}\right)$. Micropore volume $\left(V_{\text {mic }}\right)$, average pore size $\left(L_{0}\right)$, and $\mathrm{CO}_{2}$ adsorption energy $\left(E_{\text {ads }}-\mathrm{CO} 2\right)$ were obtained by application of the Dubinin-Radushkevich equation. The mesopore volume $\left(V_{\text {meso }}\right)$ was obtained through the Barrett-Joyner-Halenda (BJH) model.

\subsubsection{Chemical Composition of Nanomaterials and Sandstone}

The chemical characterization was carried out by carbon, hydrogen, oxygen and nitrogen (CHON) analysis for nanomaterials, and by Fourier transform infrared spectroscopy (FTIR) for sandstone. An IRAffinity-1S FTIR spectrometer (Shimadzu, Columbia, USA)was operated at room temperature using potassium bromide in a KBr-to-material ratio of 30:1 (\% w/w). The impregnation percentages of nanoparticles on sandstone were corroborated by thermogravimetric analysis (TGA) (TA Instruments, New Castle, USA). For this, the sample was burned under an air atmosphere at $10{ }^{\circ} \mathrm{C} \mathrm{min}^{-1}$ up to $800^{\circ} \mathrm{C}$.

\subsubsection{Rheological Analysis of CN.LYS Synthesis Solutions}

The stability of the synthesis solutions was evaluated at different concentrations of CN.LYS (CN-LYS1, CN.LYS2, and CN.LYS3). For this purpose, a Kinexus Ultra+ rheometer (Malvern Panalytical, Malvern, UK) utilizing a concentric cylinder sensor equipped with a Peltier cell for temperature control was used. The tests were first carried out by varying the shear rate from 1 to $250 \mathrm{~s}^{-1}$ in order to define the adequate shear rate $\left(50 \mathrm{~s}^{-1}\right)$. The test conditions were carried out to mimic the real synthesis conditions in terms of temperature and stirring. The process started at $60^{\circ} \mathrm{C}$ for $1 \mathrm{~h}$, after which the temperature was controlled to simulate the natural cooling process at $57,45,37$, and $34{ }^{\circ} \mathrm{C}$ until the viscosity reached a constant value. Only $30 \mathrm{~mL}$ were needed for the test, while the current reaction was carried out in $1.8 \mathrm{~L}$.

\subsubsection{Dispersion of Nanoparticles in Solution}

The electrophoretic light scattering (ELS) technique was used to evaluate the surface charge of the particles and their dispersion stability at $25{ }^{\circ} \mathrm{C}$ in a NanoPlus-3 zeta/nanoparticle analyzer (Micromeritics, Norcross, USA). In this test, several nanoparticle suspensions were prepared at $10 \mathrm{mg}$ $\mathrm{L}^{-1}$, with a pH adjusted between 2 to 12 by adding solutions of $0.1 \mathrm{~mol} \mathrm{~L}^{-1} \mathrm{HCl}$ or $0.01 \mathrm{~mol} \mathrm{~L}^{-1} \mathrm{NaOH}$, and then subjected to analysis. The zeta potential was calculated using the Smoluchowski equation, derived from the calculation of the Doppler effect.

$$
\begin{gathered}
\zeta=\eta \mathrm{U} / \varepsilon \\
U=\frac{V}{E} \\
\Delta v=2 V n \sin \left(\frac{\theta}{2}\right) / \lambda
\end{gathered}
$$

where $\zeta$ is the zeta potential, $\eta$ is the viscosity of the fluid (water), $U$ is the electrophoretic mobility, $\varepsilon$ is the permittivity, $V$ represents the speed of movement of the particles, $E$ is the electric field, $\Delta v$ is the Doppler effect, $n$ is the index of refraction, $\theta$ is the angle of detection, and $\lambda$ is the wavelength of the incident light. 


\subsection{Adsorption Tests at High Pressure}

The adsorption tests carried out below atmospheric pressure were described in sub-Section 2.3.2. At high pressure, the $\mathrm{CO}_{2}$ adsorption capacity was evaluated in two different conditions: (i) under pure $\mathrm{CO}_{2}$ in a manometric device (up to $3.0 \mathrm{MPa}$ ) and (ii) under a $\mathrm{CO}_{2} / \mathrm{N}_{2}$ flow in a gravimetric device (up to 2.6 MPa). The details of each protocol are presented below.

\subsubsection{Adsorption at High Pressure for Pure $\mathrm{CO}_{2}$-Manometric Device}

The carbon nanospheres (CN.LYS2), sandstone, and impregnated sandstone (at mass fractions of 10 and 20\%) were investigated in High Pressure Volume Analyzer, HPVAII-200 (Micromeritics, Norcross, USA) at $0{ }^{\circ} \mathrm{C}, 25^{\circ} \mathrm{C}$, and $50{ }^{\circ} \mathrm{C}$ and at pressures from $3 \times 10^{-3}$ up to $3.0 \mathrm{MPa}$. In order to have enough total surface area for adsorption and to minimize measurement errors, the amount of each material inside the sample holder was around $0.5 \mathrm{~g}$ for nanoparticles, $1.5 \mathrm{~g}$ for impregnated sandstone, and $14 \mathrm{~g}$ for sandstone. The contribution of the empty sample holder was systematically measured and subtracted to all data to improve accuracy. The isosteric heat of adsorption, $Q_{S T}$, was calculated using the isosteric method with the Microactive software (from Micromeritics, Norcross, USA) from three adsorption isotherms at 0,25 , and $50^{\circ} \mathrm{C}$, based on the Clausius-Clapeyron equation [51]:

$$
-\frac{Q_{S T}}{R}=\frac{\partial \ln (P)}{\partial(1 / T)}
$$

where $R$ is the universal gas constant $\left(8.314 \mathrm{~J} \mathrm{~mol}^{-1} \mathrm{~K}^{-1}\right), P$ is the absolute pressure, and $T$ is the temperature.

The excess adsorbed $\mathrm{CO}_{2}$ amount $\left(N_{\text {exc }}, \mathrm{g}_{\mathrm{CO} 2} \cdot \mathrm{g}_{\text {adsorbent }}{ }^{-1}\right)$ was equal to the absolute adsorbed $\mathrm{CO}_{2}$ amount $\left(\mathrm{N}_{\mathrm{ads}}, \mathrm{g}_{\mathrm{CO} 2} \cdot \mathrm{g}_{\text {adsorbent }}{ }^{-1}\right)$ minus the product of gas density in the bulk phase by the volume of the adsorbed phase. The values provided by the HPVA device were obtained on an excess basis, and therefore, the absolute amounts had to be determined as follows [52]:

$$
N_{a d s}=N_{e x c}\left(1+\frac{P+M_{\mathrm{CO} 2}}{Z \rho_{\text {liq }} R T}\right)
$$

where $M_{\mathrm{CO} 2}$ is the molecular weight of $\mathrm{CO}_{2}\left(44.013 \mathrm{~g} \mathrm{~mol}^{-1}\right), \mathrm{Z}$ is the compressibility factor at the considered pressure and temperature, and $\rho_{\text {liq }}$ is the density of liquid $\mathrm{CO}_{2}\left(1032 \times 10^{3} \mathrm{~g} \mathrm{~m}^{-3}\right)$.

The isotherms were fitted with the Sips and Toth models, which take into account multilayer adsorption. Table 1 presents the equations for each model [53-55]. $K_{\mathrm{S}}$ and $K_{\mathrm{T}}$ represent adsorption equilibrium constants for the Sips and Toth models, respectively, and the $n$ and $t$ parameters indicate the heterogeneity of the system for the Sips and Toth models, respectively. The heterogeneity may originate from the solid structure, from the solid energy properties, or from the adsorbate [54]. The $n$ or $t$ parameters are usually greater than unity, and when they are the unit, the models assume the Langmuir equation [54].

$$
\begin{aligned}
& N_{a d s}=N_{m} \frac{\left(K_{S} P\right)^{1 / n}}{1+\left(K_{S} P\right)^{1 / n}} \\
& N_{a d s}=N_{m} \frac{\left(K_{T} P\right)^{1 / t}}{1+\left(K_{T} P\right)^{1 / t}}
\end{aligned}
$$


Table 1. Models for adsorption isotherms.

\begin{tabular}{cl}
\hline Model & \multicolumn{1}{c}{ Pquations } \\
Sips & $\begin{array}{l}N_{\mathrm{ads}}\left(\mathrm{mmol} \mathrm{g}^{-1}\right) \text { is the adsorbed amount, } N_{\mathrm{m}}(\mathrm{mmol} \\
\left.\mathrm{g}^{-1}\right) \text { is the adsorption capacity at equilibrium, } P(\mathrm{kPa}) \\
\text { is the equilibrium pressure, and } K_{\mathrm{S}} \text { and } n \text { are the Sips } \\
\text { adsorption equilibrium constants, related to the } \\
\text { affinity and the heterogeneity of the system, } \\
\text { respectively. }\end{array}$ \\
\hline Toth & $\begin{array}{l}N_{\text {ads }}, N_{\mathrm{m}}, \text { and } P \text { have the same meaning as above, } \\
\text { and } K_{\mathrm{T}} \text { and } t \text { are the Toth adsorption equilibrium } \\
\text { constants, related to the affinity and the } \\
\text { heterogeneity of the system, respectively. }\end{array}$ \\
\hline
\end{tabular}

\subsubsection{Adsorption at High Pressure for $\mathrm{CO}_{2}$ and $\mathrm{N}_{2}$-Gravimetric Device}

The CN.LYS2, sandstone, and impregnated sandstone $\mathrm{CO}_{2}$ isotherms (with a mass fraction of $20 \%$ of nanoparticles) were investigated using a HP TGA 750 thermogravimetric analyzer (TA Instruments, New Castle, USA) at $50{ }^{\circ} \mathrm{C}$ and high pressure from 0.03 to $3.0 \mathrm{MPa}$ for $\mathrm{CO}_{2}$ and $\mathrm{N}_{2}$. This device was equipped with a magnetic levitation top-loading balance, which made it possible to achieve high accuracy and reduce the volume of the system. The amount of each material put inside the sample holder was around $15 \mathrm{mg}$ for nanoparticles, $40 \mathrm{mg}$ for sandstone, and $40 \mathrm{mg}$ for impregnated sandstone, to have enough total surface area for adsorption. The contribution of the buoyancy effect was manually subtracted from the data using blank tests carried out in the same conditions but with an empty sample holder. From the adsorption results of each $\mathrm{N}_{2}$ and $\mathrm{CO}_{2}$ isotherm, it was possible to predict the selectivity by applying the ideal adsorbed solution theory (IAST), which allows estimating the competitive adsorption of the compounds in a mixture of gases as the flue gas. Based on the literature, a model flue gas comprising $80 \% \mathrm{~N}_{2}$ and $20 \% \mathrm{CO}_{2}$ was selected. The IAST was implemented in a Python routine (package-pyIAST from Simon et al. [56]).

\section{Results and Discussion}

The results are divided into two main sections: (a) materials characteristics (nanoparticles and sandstone) and (b) study of the interaction between $\mathrm{CO}_{2}$ /nanoparticles/sandstone by adsorption isotherms under different operation conditions $(T, P)$.

\subsection{Materials Characteristics}

The morphology of the carbon materials obtained from melamine and carbon tetrachloride was very heterogeneous. Figure $2 \mathrm{a}, \mathrm{b}$ presents SEM images of two different zones wherein more or less agglomerated nanospheres can be observed (Figure 2b). When the images are observed at lower magnification, it can be noticed that some areas have fiber and block morphologies (Figure 2c), while other areas have nanospheres/microspheres morphologies (Figure 2d).

After coating with resorcinol/formaldehyde, the hydrodynamic diameter of the CN.MEL particles was higher than the limit of detection of the equipment $(10 \mu \mathrm{m})$. For the e-CCS process, this material might, thus, induce technical problems, due to the possible obstruction of the naturally porous structure of the rock. The ultimate analysis (Table 2) shows that this material had a nitrogen content close to $50 \%$ before coating and carbonization (Gel.MEL1), but of only $9.2 \%$ after coating with resorcinol/formaldehyde (Gel.MEL2) and 2.2\% after carbonization (CN.MEL). Therefore, CN.LYS and CN.MEL materials exhibited similar nitrogen contents. Some N-rich carbon materials, reported in the literature, have nitrogen content close to those obtained in this work [16]. The oxygen content was measured independently from carbon, hydrogen and nitrogen content. 


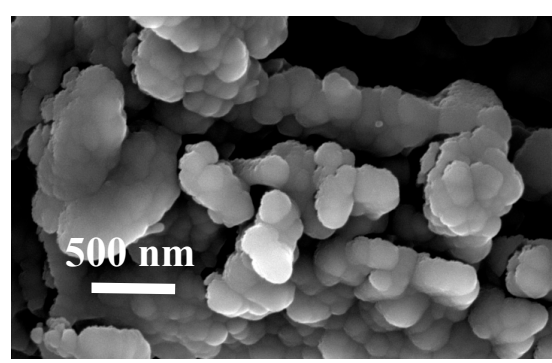

(a)

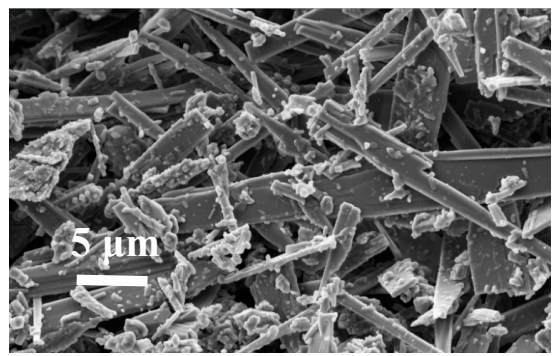

(c)

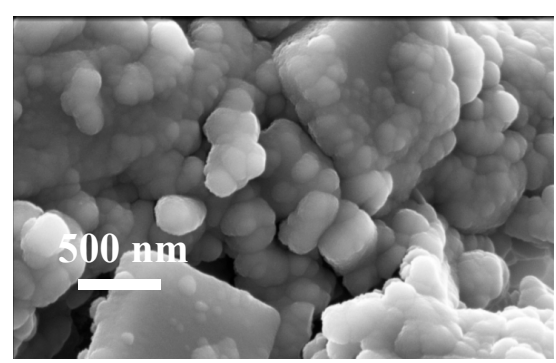

(b)

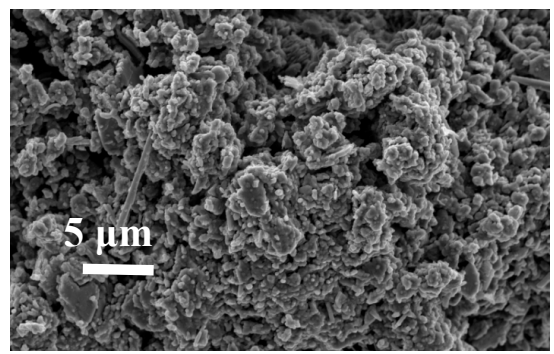

(d)

Figure 2. SEM images at $5 \mathrm{kV}$ of carbon nanospheres from melamine (CN.MEL) before resorcinol/formaldehyde coating and final pyrolysis: $(\mathbf{a}, \mathbf{b})$ nanospheres and build fibers and blocks; (c) area with structures in the form of fibers and blocks, and (d) distribution of nanospheres, fibers, and blocks.

Table 2. Ultimate analysis of nanoparticles synthesized with melamine (CN.MEL) and L-lysine (CN.LYS).

\begin{tabular}{ccccc}
\hline & C (Mass Fraction \%) & H (Mass Fraction \%) & N (Mass Fraction \%) & O (Mass Fraction \%) \\
\hline Gel.MEL1 & 22.8 & 4.7 & 49.1 & 7.3 \\
Gel.MEL2 & 55.9 & 5.0 & 9.2 & 31.0 \\
CN.MEL & 85.6 & 2.3 & 2.2 & 10.2 \\
Gel.LYS1 & 59.5 & 6.7 & 5.1 & 31.9 \\
Gel.LYS2 & 61.7 & 6.7 & 5.0 & 31.6 \\
Gel.LYS3 & 62.7 & 6.4 & 5.0 & 28.3 \\
CN.LYS1 & 88.6 & 1.7 & 1.7 & 9.9 \\
CN.LYS2 & 91.1 & 1.7 & 1.9 & 12.0 \\
CN.LYS3 & 91.9 & 2.1 & 2.2 & 12.8 \\
\hline
\end{tabular}

The Gel.MEL1 (49.1\% of nitrogen) was submitted to $\mathrm{CO}_{2}$ and $\mathrm{N}_{2}$ adsorption (at $0{ }^{\circ} \mathrm{C}$ and $-196{ }^{\circ} \mathrm{C}$, respectively) but it was impossible to obtain the corresponding isotherms, possibly because of its too low surface area. It is well known that the pyrolysis step induces a significant increase of narrow porosity by elimination of volatile species. However, when the Gel.MEL1 is directly pyrolyzed, most of the material undergoes decompositions and the yield is very low $(<5 \%)$.

The adsorption and desorption isotherms $\left(\mathrm{N}_{2}\right.$ at $-196{ }^{\circ} \mathrm{C}$ and $\mathrm{CO}_{2}$ at $\left.0{ }^{\circ} \mathrm{C}\right)$ for nanomaterials synthesized with melamine (CN.MEL) and L-lysine (CN.LYS) are presented in Figure 3, and the textural parameters obtained from adsorption isotherms are presented in Table 3.

The micropore and the mesopore fractions of the CN.MEL and CN.LYS2 materials were similar (67-64\% and 33-36\%, respectively) although their total pore volumes (at $\left.P / P_{0}=0.95\right)$ were rather different. Both CN.LYS1 and CN.LYS3 exhibited higher micropore fractions (72.7 and $92.3 \%$, respectively), but had lower values of $A_{\mathrm{BET}}$ and total pore volumes than those of CN.MEL and CN.LYS2 materials (Figure 3). The mesoporous volumen of CN.MEL is evidenced by the hysteresis loop in the range of relative 
pressures between 0.46 and 0.66 . In the CN.LYS series, only CN.LYS2 was also mesoporous, but with a different structure as deduced from the different shape of the hysteresis loop, occurring at higher relative pressure. The CN.LYS1 texture was moderately mesoporous (28.6\%). After the first dilution, the CN.LYS2 texture was a little more mesoporous (36.6\%), but after the third dilution, CN.LYS3 had a predominantly microporous texture as evidenced by the type Ia of its $\mathrm{N}_{2}$ isotherm. The adsorption capacity of $\mathrm{CO}_{2}$ at $0{ }^{\circ} \mathrm{C}$ was as expected according to the range reported in the literature, but the synthesis process reported in this study was easier than many others reported so far $[16,43,57]$. The experimental development considered important parameters for a possible industrial application, such as operation at atmospheric pressure, relatively low temperature $\left(60^{\circ} \mathrm{C}\right)$, and relatively low time $(1 \mathrm{~h})$ before carbonization. The carbon nanospheres are usually synthesized by methods that demand greater energy and time [29].

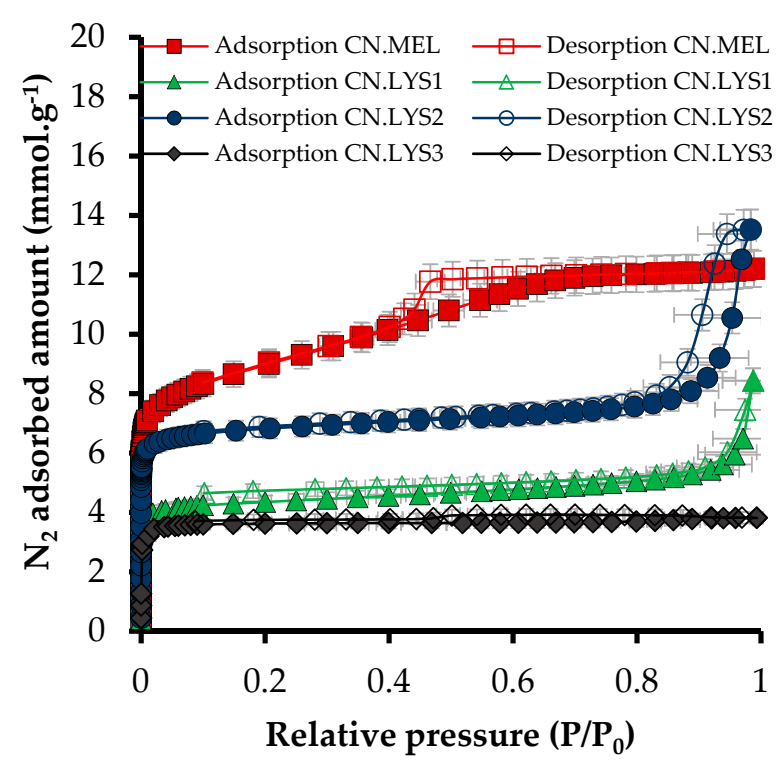

(a)

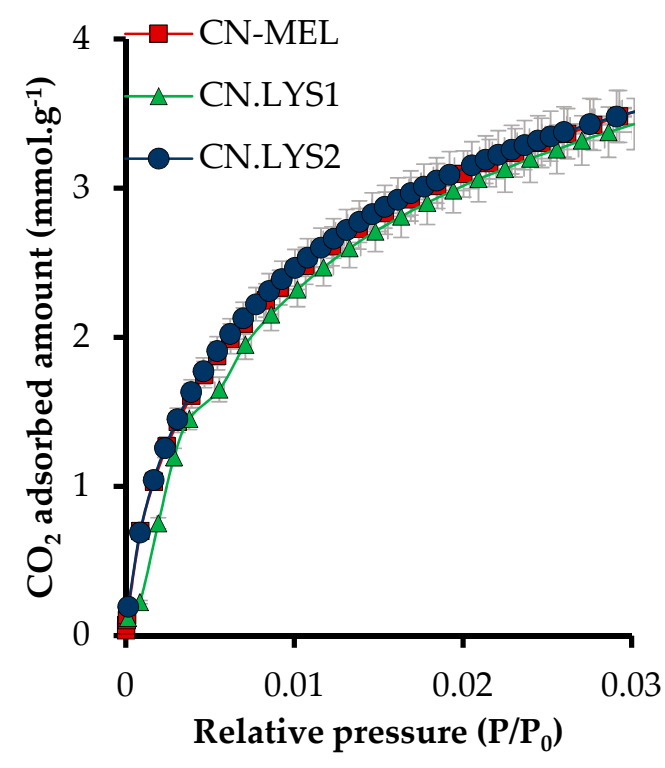

(b)

Figure 3. Adsorption (full symbols) and desorption (empty symbols) isotherms at atmospheric pressure for nanoparticles synthesized with melamine (CN.MEL) and L-lysine (CN.LYS). (a) $\mathrm{N}_{2}$ at $-196{ }^{\circ} \mathrm{C}$ and (b) $\mathrm{CO}_{2}$ at $0{ }^{\circ} \mathrm{C}$.

Table 3. Parameters obtained from adsorption isotherms $\left(\mathrm{N}_{2}\right.$ at $-196{ }^{\circ} \mathrm{C}$ and $\mathrm{CO}_{2}$ at $\left.0{ }^{\circ} \mathrm{C}\right)$ for nanomaterials synthesized with melamine (CN.MEL) and L-lysine (CN.LYS).

\begin{tabular}{|c|c|c|c|c|c|c|c|}
\hline & $\begin{array}{c}A_{B E T} \\
\left(m^{2} g^{-1}\right)\end{array}$ & $\begin{array}{c}V_{0.95} \\
\left(\mathrm{~cm}^{3} \mathrm{~g}^{-1}\right)\end{array}$ & $\begin{array}{c}V_{\text {mic-N2 }} \\
\left(\mathrm{cm}^{3} \mathrm{~g}^{-1}\right)\end{array}$ & $\begin{array}{l}V_{\text {mic-CO2 }} \\
\left(\mathrm{cm}^{3} \mathrm{~g}^{-1}\right)\end{array}$ & $\begin{array}{c}V_{\text {mes }} \\
\left(\mathrm{cm}^{3} \mathrm{~g}^{-1}\right)\end{array}$ & $\begin{array}{c}\mathrm{L}_{0} \\
(\mathrm{~nm})\end{array}$ & $\begin{array}{c}\mathrm{E}_{\mathrm{ads} . \mathrm{CO} 2} \\
\left(\mathrm{~kJ} \mathrm{\textrm {mol } ^ { - 1 } )}\right.\end{array}$ \\
\hline CN.MEL & 713 & 0.42 & $0.28(66.6 \%)$ & 0.26 & 0.14 & 0.77 & 30.9 \\
\hline CN.LYS1 & 385 & 0.22 & $0.16(72.7 \%)$ & 0.18 & 0.06 & 0.84 & 32.4 \\
\hline CN.LYS2 & 612 & 0.36 & $0.23(63.9 \%)$ & 0.25 & 0.13 & 0.56 & 31.6 \\
\hline CN.LYS3 & 320 & 0.13 & 0.12 (92.3\%) & - & 0.01 & 0.62 & - \\
\hline
\end{tabular}

In order to provide explanations of the aforementioned trends, Figure 4 presents TEM pictures of Gel.LYS (materials before carbonization) and CN.LYS (materials after carbonization).

Figure 4a,b present CN.LYS1 before and after carbonization, respectively. Here a mixture of larger and smaller nanospheres can be seen. Figure $4 c$,d present smaller particles (approximately $50 \mathrm{~nm}$ ) for CN.LYS2 before and after carbonization. These particles are more transparent than those of the CN.LYS1 and CN.LYS3 materials, due to the more mesoporous texture of the CN.LYS2 material. Figure $4 \mathrm{e}, \mathrm{f}$ present CN.LYS3 before and after carbonization. It can be seen that a gel was formed around the spheres. The L-lysine acts as a catalyst in the reaction, and therefore, if its amount is limited for the 
third dilution process, it might be the reason for the formation of a gel coating the spheres instead of producing more nanospheres, which obstructs the porous structure of CN.LYS3. This would affect the results presented in Figure 3 and Table 3 for CN.LYS3. The reproducibility for CN.LYS is significant, the variation of size and $\mathrm{CO}_{2}$ capacity is less than $1 \%$.

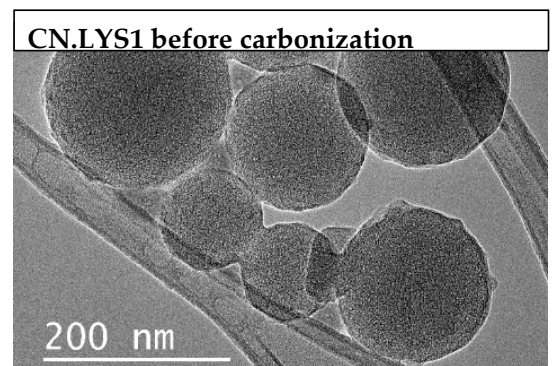

(a)

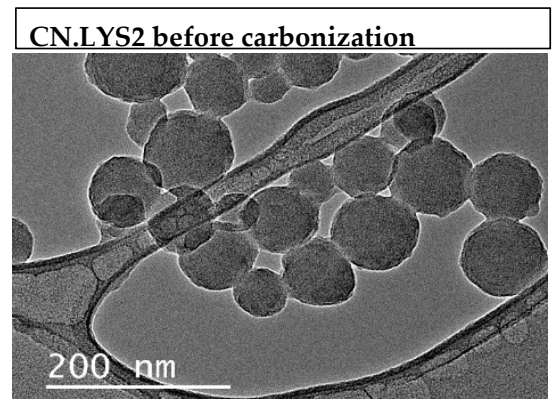

(c)

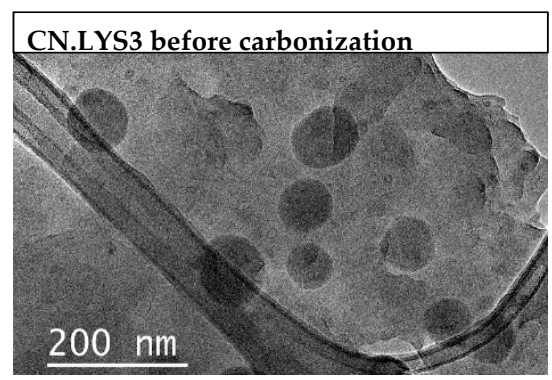

(e)

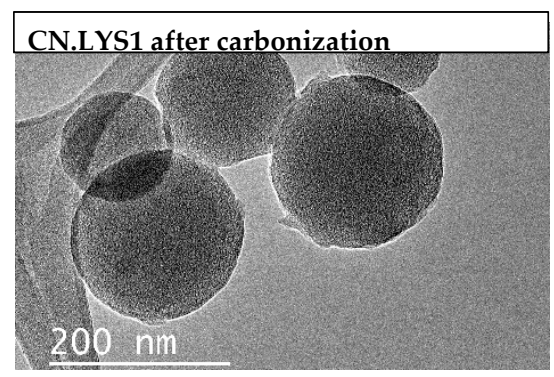

(b)

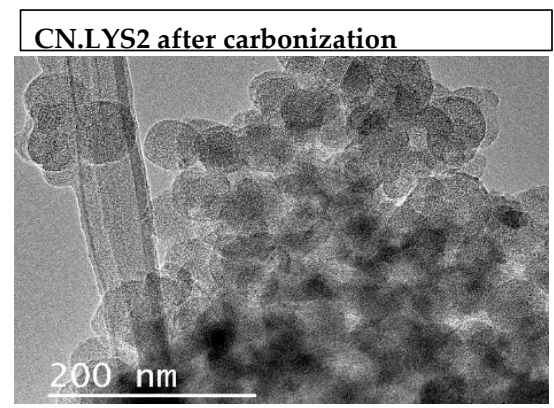

(d)

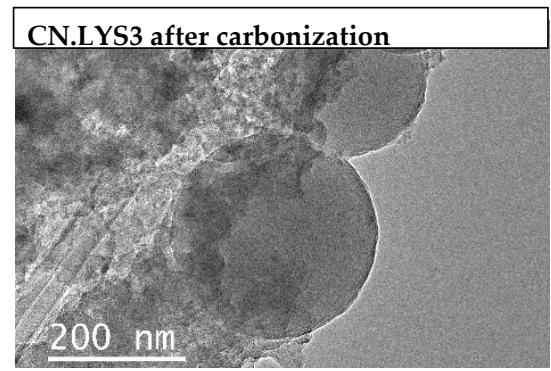

(f)

Figure 4. TEM images of carbon nanospheres synthesized with L-lysine. (a) Gel.LYS1, (b) CN.LYS1, (c) Gel.LYS2, (d) CN.LYS2, (e) Gel.LYS3, and (f) CN.LYS3.

Figure 5 presents the rheological behavior of the synthesis solution/colloid/suspension (Sol.LYS1 without dilution, Sol.LYS2 for dilution 1, and Sol.LYS3 for dilution 2). The changes in temperature and the stirring were chosen to reproduce the conditions of synthesis $\left(60^{\circ} \mathrm{C}\right.$ for $1 \mathrm{~h}$ and after cooling at room temperature). The cooling stage was controlled in the rheometer. The viscosity has changed during synthesis because the reactive system underwent polymerization and condensation-related changes to form the nanospheres, so that the system passed from the solution to the colloid and the suspension. The differences in viscosity were related to the concentration of reagents in the solutions. The third solution, Sol.LYS3, presented fewer changes during the synthesis process because the system had a lower concentration of reagents as presented in Figure 4.

Based on the particle size analysis, porous texture, nitrogen content, and adsorbed amount of $\mathrm{CO}_{2}$ (at $0{ }^{\circ} \mathrm{C}$ and up to $1 \mathrm{bar}$ ), the CN.LYS material was selected to perform the adsorption tests in conditions closer to those of the reservoir. Despite the high $\mathrm{CO}_{2}$ adsorption capacities exhibited by the CN.MEL material, its size and shape would not allow its application in real reservoir conditions. Besides, its synthesis process was more complex, with a higher number of steps and a higher consumption 
of energy and time, which were not compensated by significantly better physicochemical properties regarding the CN.LYS.

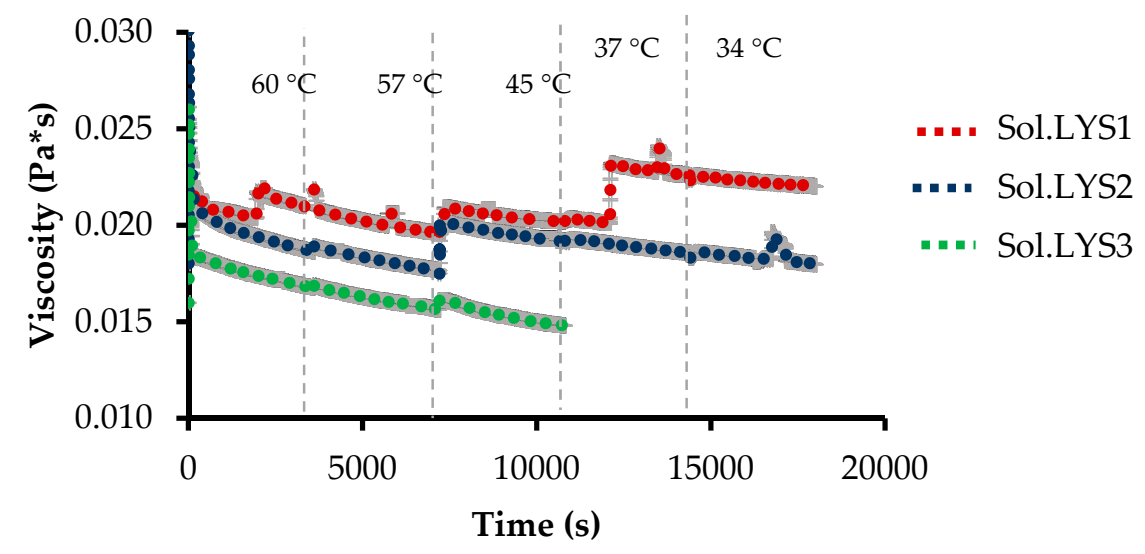

Figure 5. Rheological analysis of synthesis solutions with L-Lysine (Sol.LYS) in the same thermal conditions but with different resorcinol/water molar ratios: 1:2778 (Sol.LYS1), 1:5556 (Sol.LYS2), and 1:11112 (Sol.LYS3).

To analyze the behavior of the nanoparticles in aqueous medium, Table 4 presents the mean particle size of nanomaterials (CN.LYS) and Figure 6 presents their zeta potentials. According to the Stokes-Einstein equation, the diffusion coefficient is inversely proportional to particle size or hydrodynamic diameter; therefore, it is possible to analyze whether the nanoparticles could interact to form aggregates. Precipitation is only possible if the aggregates are big enough. Another important concept is zeta potential; if zeta potential is high (negative or positive), the particles are stable due to the high electrostatic repulsion between them. On the contrary, a low zeta potential (approaching zero) increases the probability of particles colliding, and thus forming aggregates. The hydrodynamic diameter was calculated for nanoparticles in water (at pH 5.8) and ethanol (at pH 7). Aggregate size was less in ethanol (Table 4) because the $\mathrm{pH}$ affects the behavior in solution (Figure 6). However, the results for nanoparticles suspended in water was close those obtained for nanoparticles suspended in ethanol. For an industrial application and injection into the porous medium, the most economical way is suspension in water.

Table 4. Mean particle size of nanomaterials in suspension, synthesized with L-lysine.

\begin{tabular}{ccc}
\hline Material & $\boldsymbol{d}_{\mathbf{p}} \mathbf{5 0}(\mathbf{n m})$ in Water $\mathbf{( p H ~ 5 . 8 )}$ & $\boldsymbol{d}_{\mathbf{p}} \mathbf{5 0}(\mathbf{n m})$ in Ethanol (pH 7) \\
\hline Gel.LYS1 & 579.4 & 361.5 \\
Gel.LYS2 & 314.2 & 274.2 \\
Gel.LYS3 & 1083.4 & 1957.1 \\
CN.LYS1 & 801.1 & 785.9 \\
CN.LYS2 & 242.6 & 239.9 \\
CN.LYS3 & 2828.7 & 2587.4 \\
\hline
\end{tabular}

For CN.LYS1 and CN.LYS3, a pH higher than 7 was better for rocks impregnation because the zeta potential was farther from zero. For CN.LYS2, a pH higher than 7 or lower than 4.7 was better for rocks impregnation. Gel.LYS2 presented the highest values of zeta potential at $\mathrm{pH}$ below 4 , increasing the natural precipitation time of nanoparticles after the synthesis process.

Figure 7 presents SEM images of the sandstone surface before (Figure $7 \mathrm{a}$ ) and after (Figure $7 \mathrm{~b}, \mathrm{c}$ ) the impregnation step. Impregnation was achieved in water because of its lower cost and non-hazardous nature, making it ideal for industrial applications. The distribution of CN.LYS2 particles was homogeneously distributed on the surface (Figure $7 \mathrm{~b}$ ). The size of the aggregates was between 100 and $200 \mathrm{~nm}$ (Figure 7b). After one year, the sandstone continued to be impregnated, without showing any 
disintegration of nanoparticles from the sandstone surface. By thermogravimetric analysis, variations of less than $5 \%$ of the percentage of impregnation were obtained. This can also be related to the impregnation method without stirring, which might produce zones of lower nanoparticle concentration.

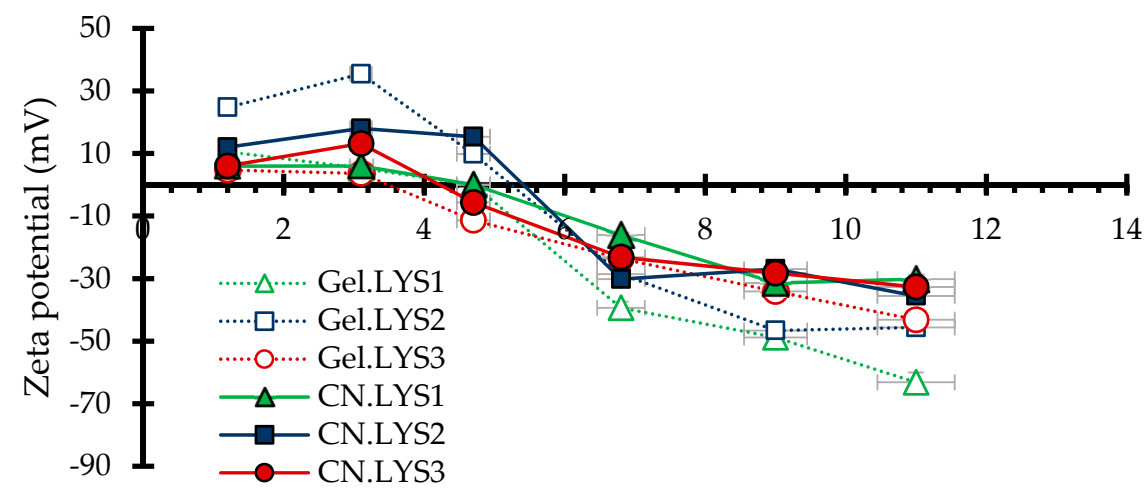

$\mathrm{pH}$

Figure 6. Zeta potential for carbon nanoparticles synthesized with L-lysine.

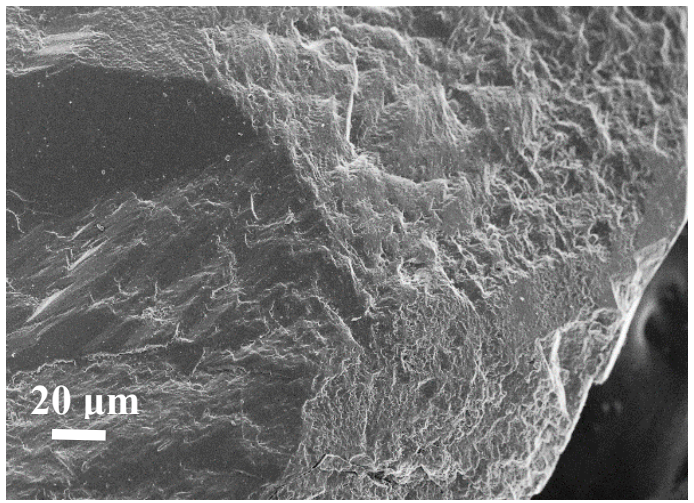

(a)

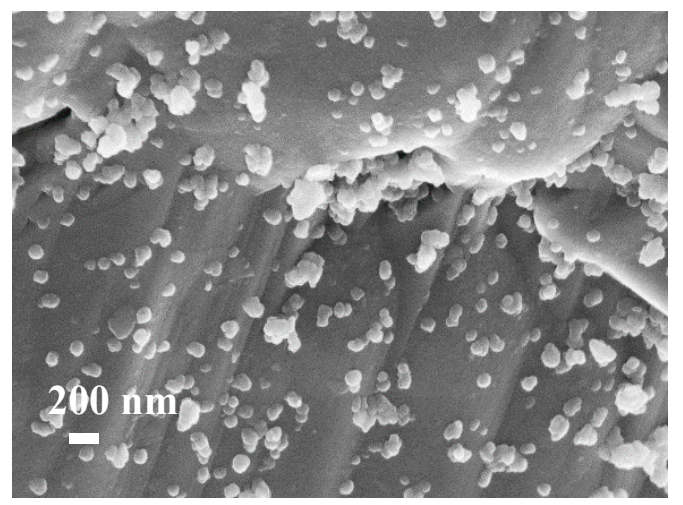

(b)

Figure 7. SEM images of (a) sandstone and (b) sandstone impregnated with a mass fraction of $20 \%$ of CN.LYS2.

The sandstone presented an $A_{\mathrm{BET}}$ of $0.4 \mathrm{~m}^{2} \mathrm{~g}^{-1}$, and its $\mathrm{CO}_{2}$ adsorption capacity could not be measured using conventional methods $\left(<0.0013 \mathrm{mmol} \mathrm{g}^{-1}\right.$ at $0^{\circ} \mathrm{C}$ and atmospheric pressure). Sandstone is mainly composed of silica, which has an acidic character as the $\mathrm{CO}_{2}$ molecule. Consequently, if the specific area of the sandstone is low, its $\mathrm{CO}_{2}$ adsorption capacity is even lower than that which might be expected for this specific area.

The sandstone was impregnated at a low nanoparticle concentration to evaluate its economic feasibility at the industrial level. The sandstone impregnated with mass fractions of 0.1 and $0.01 \%$ did not show a significant increase in its surface properties, unlike samples with higher mass fractions as shown in Table 5. The textural parameters of the impregnated sandstones were indeed improved as the percentage of nanoparticles on their surface increased. At a mass fraction of $20 \%, A_{\mathrm{BET}}$ and $V_{0.95}$ increased by factors as high as 225 and 670, respectively.

Figure 8 shows adsorption isotherms of $\mathrm{CO}_{2}$ at atmospheric pressure and $0{ }^{\circ} \mathrm{C}$, for raw sandstone and sandstone impregnated at mass fractions of $0.01,0.1,1,5,10$, and $20 \%$ of CN.LYS2. In addition, it shows the slope changes related to the affinity between the adsorbent medium and the adsorbate. The materials did not have significant affinity with $\mathrm{CO}_{2}$ at mass fractions of 0.01 and $0.1 \%$ and without CN.LYS2. The affinity and adsorption capacity increased with the percentage of nanoparticles in the system. The latter presented a different behavior above a mass fraction of $1 \%$. Indeed, at a mass 
fraction of $1 \%$, the adsorption capacity was increased by a factor 21 with respect to raw sandstone, although the value was still low, $0.03 \mathrm{mmol} \mathrm{g}^{-1}$. At a mass fraction of $20 \%$, the value was far higher, $0.63 \mathrm{mmol} \mathrm{g}^{-1}$, corresponding to an increment factor of 499. Different materials have been reported in the literature $[16,43]$ with specific surface modifications to increase the adsorption capacity of $\mathrm{CO}_{2}$, but the value of adsorption capacity was similar to that of sandstone by adding a mass fraction of 10 or $20 \%$ of nanoparticles.

Table 5. Parameters obtained from adsorption isotherms $\left(\mathrm{N}_{2}\right.$ at $-196{ }^{\circ} \mathrm{C}$ and $\mathrm{CO}_{2}$ at $\left.0{ }^{\circ} \mathrm{C}\right)$ for sandstone impregnated with mass fractions of $1,5,10$, and $20 \%$ of CN.LYS2.

\begin{tabular}{ccccccc}
\hline & $\begin{array}{c}\mathbf{A}_{\text {BET }} \\
\left(\mathbf{m}^{\mathbf{2}} \mathbf{g}^{-\mathbf{1}}\right)\end{array}$ & $\begin{array}{c}\mathbf{V}_{\mathbf{0 . 9 5}} \\
\left(\mathbf{c m}^{\mathbf{3}} \mathbf{g}^{\mathbf{- 1}}\right)\end{array}$ & $\begin{array}{c}\mathbf{V}_{\text {mic-N2 }} \\
\left(\mathbf{c m}^{\mathbf{3}} \mathbf{g}^{-\mathbf{1}}\right)\end{array}$ & $\begin{array}{c}\mathbf{V}_{\text {mic-CO2 }} \\
\left(\mathbf{c m}^{\mathbf{3}} \mathbf{g}^{-\mathbf{1}}\right)\end{array}$ & $\begin{array}{c}\mathbf{V}_{\text {mes }} \\
\left(\mathbf{c m}^{\mathbf{3}} \mathbf{g}^{\mathbf{1}}\right)\end{array}$ & $\mathbf{L}_{\mathbf{0}}(\mathbf{n m})$ \\
\hline SS-1 & 2 & 0.003 & 0.002 & 0.002 & 0.001 & 0.56 \\
SS-5 & 20 & 0.016 & 0.01 & 0.012 & 0.006 & 0.53 \\
SS-10 & 49 & 0.035 & 0.021 & 0.023 & 0.014 & 0.51 \\
SS-20 & 99 & 0.067 & 0.042 & 0.044 & 0.025 & 0.52 \\
\hline
\end{tabular}

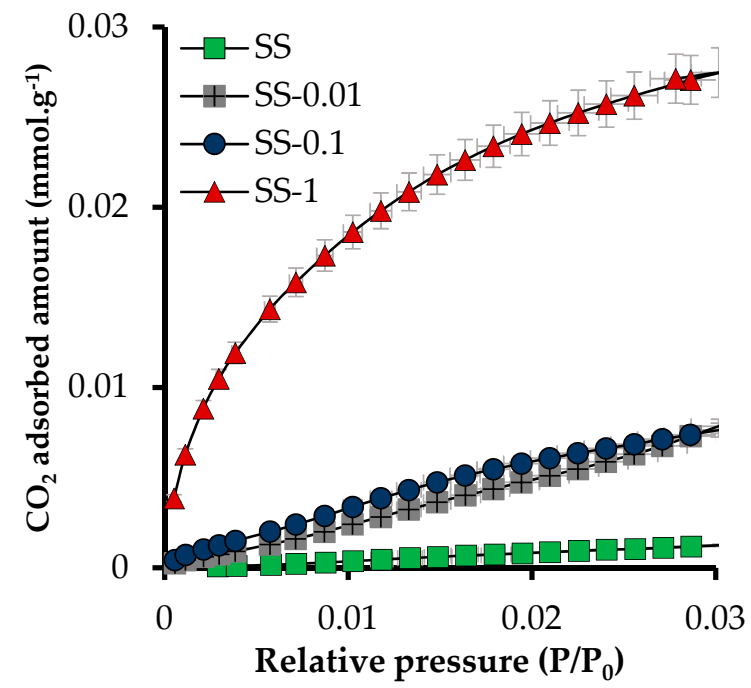

(a)

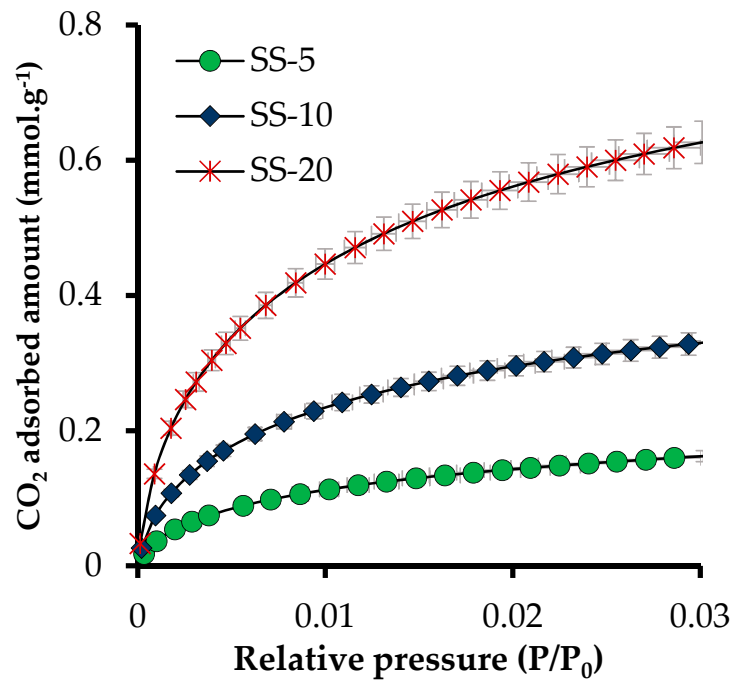

(b)

Figure 8. Adsorption isotherms of $\mathrm{CO}_{2}$ at atmospheric pressure and $0{ }^{\circ} \mathrm{C}$. (a) Mass fractions $\leq 1 \%$ and (b) mass fractions $\geq 5 \%$.

The effect of the impregnation method on the $\mathrm{CO}_{2}$ adsorption capacity at atmospheric pressure and $0^{\circ} \mathrm{C}$ was then evaluated. As explained before, immersion and soaking were achieved using two different sets of conditions: (i) $6 \mathrm{~h}$ and $600 \mathrm{rpm}$ and (ii) $24 \mathrm{~h}$ without stirring. Increasing the soaking time by $18 \mathrm{~h}$ improved the adsorption capacity by more than $25 \%$ (Table 6 ). The values presented in Figure 8 , adsorption isotherms of $\mathrm{CO}_{2}$ at atmospheric pressure and $0{ }^{\circ} \mathrm{C}$, thus correspond to Conditions 2 .

Table 6. Relationship between soaking time and adsorption capacity of $\mathrm{CO}_{2}$ at atmospheric pressure, $0{ }^{\circ} \mathrm{C}$ and mass fractions of 5, 10, and 20\%. Conditions 1: $6 \mathrm{~h}$ and $600 \mathrm{rpm}$; Conditions 2: $24 \mathrm{~h}$ without stirring.

\begin{tabular}{cccc}
\hline & $\mathbf{5 \%}$ & $\mathbf{1 0}$ & $\mathbf{2 0} \%$ \\
\hline Conditions 1 $\left(\mathrm{mmol} \mathrm{g}^{-1}\right)$ & 0.12 & 0.27 & 0.49 \\
Conditions 2 $\left(\mathrm{mmol} \mathrm{g}^{-1}\right)$ & 0.16 & 0.33 & 0.63 \\
\hline Increment $(\%)$ from conditions 1 to 2 & 40.5 & 25.4 & 27.2 \\
\hline
\end{tabular}


To evaluate the possible synergistic behavior between NC.LYS2 and sandstone, the theoretical and experimental values of the $\mathrm{CO}_{2}$ adsorption capacity are presented in Table 7. Theoretical values were calculated by assuming a linear relationship and taking into account the $\mathrm{CO}_{2}$ adsorption capacities and the percentages of each solid. The difference between theoretical and experimental values ranged from 5 to 10\%, which corresponds to the experimental error given the inaccuracy in the measurement of the very low $\mathrm{CO}_{2}$ adsorption capacity of the sandstone. The differences could also be related to the segregation of nanoparticles during the impregnation process, the nanoparticles not being homogeneously distributed on the surface of the sandstone.

Table 7. $\mathrm{CO}_{2}$ adsorption capacity at atmospheric pressure, $0^{\circ} \mathrm{C}$, and mass fractions of $1,5,10$, and $20 \%$.

Theoretical and experimental values.

\begin{tabular}{ccccc}
\hline & $\mathbf{1 \%}$ & $\mathbf{5 \%}$ & $\mathbf{1 0} \%$ & $\mathbf{2 0} \%$ \\
\hline Theoretical $\mathrm{N}_{\text {ads }}\left(\mathrm{mmol} \mathrm{g}^{-1}\right)$ & 0.036 & 0.175 & 0.349 & 0.697 \\
Experimental $\mathrm{N}_{\text {ads }}\left(\mathrm{mmol} \mathrm{g}^{-1}\right)$ & 0.027 & 0.162 & 0.333 & 0.627 \\
\hline Relative difference $(\%)$ & 23.8 & 7.4 & 4.7 & 10.1 \\
\hline
\end{tabular}

\subsection{High-Pressure Adsorption Tests}

\subsubsection{Pure $\mathrm{CO}_{2}$ Adsorption at High Pressure-Manometric Measurement Method}

The e-CCS process requires evaluating the behavior of the materials at high pressure (up to $3 \mathrm{MPa}$ ) and at the temperature of a hypothetical reservoir $\left(50^{\circ} \mathrm{C}\right)$. Figure $9 \mathrm{a}-\mathrm{c}$ present the absolute $\mathrm{CO}_{2}$ adsorbed amount and the excess amount for CN.LYS2 at 0,25 , and $50^{\circ} \mathrm{C}$. The difference between excess and absolute amounts appeared above $1 \mathrm{MPa}$, and represented $8.3 \%$ at $0{ }^{\circ} \mathrm{C}, 6.7 \%$ at $25{ }^{\circ} \mathrm{C}$, and $5.9 \%$ at $50{ }^{\circ} \mathrm{C}$. This difference was lower when the temperature increased. Such a trend is consistent with the fact that, at similar pressure, the density of the bulk phase decreases when the temperature increases. The high-pressure intrinsic $\mathrm{CO}_{2}$ adsorption capacity of sandstone without impregnation had a negligible effect on the measurement. Therefore, the evaluation was only carried out for sandstone impregnated at mass fractions of $10 \%$ and $20 \%$ (Figure $9 \mathrm{~d}$,e). The difference between excess and absolute adsorbed amounts of impregnated sandstone was similar to that of CN.LYS2, stranded out after $1 \mathrm{MPa}$, and represented less than $10 \%$, on average.

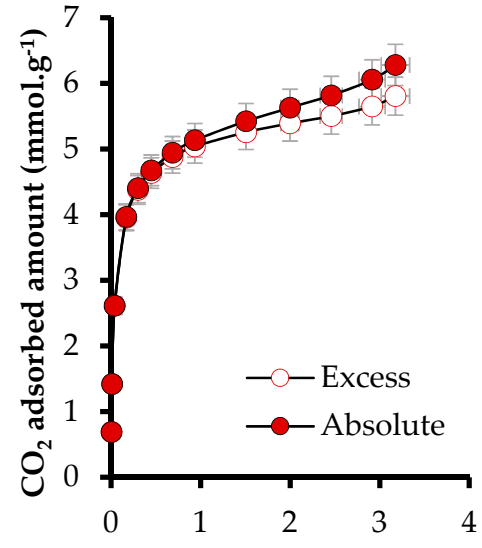

Absolute pressure (MPa)

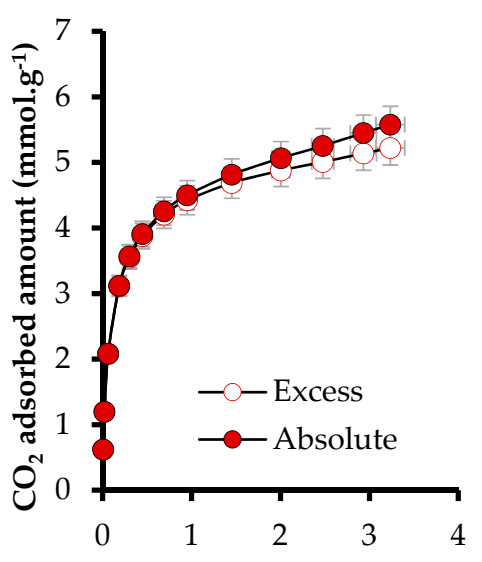

Absolute pressure (MPa)

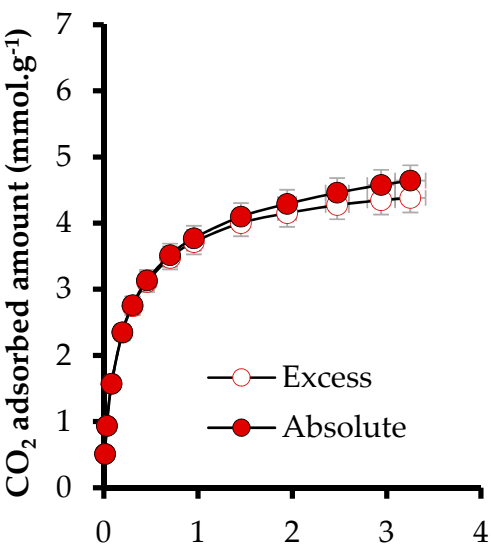

Absolute pressure (MPa)

(a)

(b)

(c)

Figure 9. Cont. 


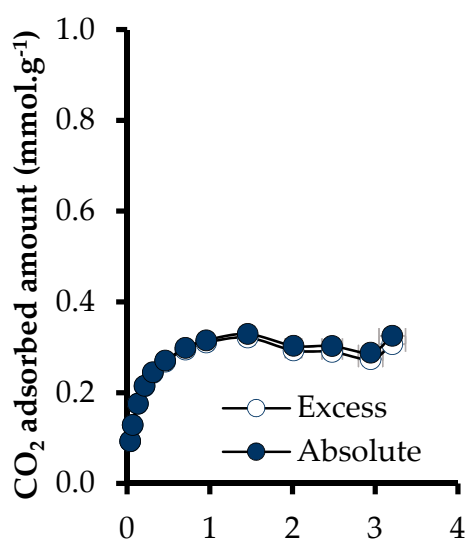

Absolute pressure (MPa)

(d)

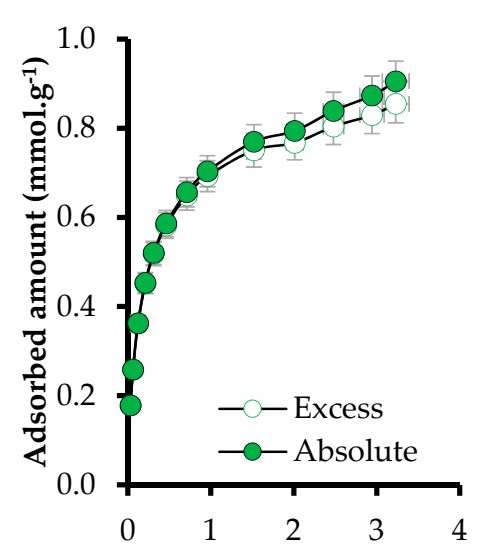

Absolute pressure (MPa)

(e)

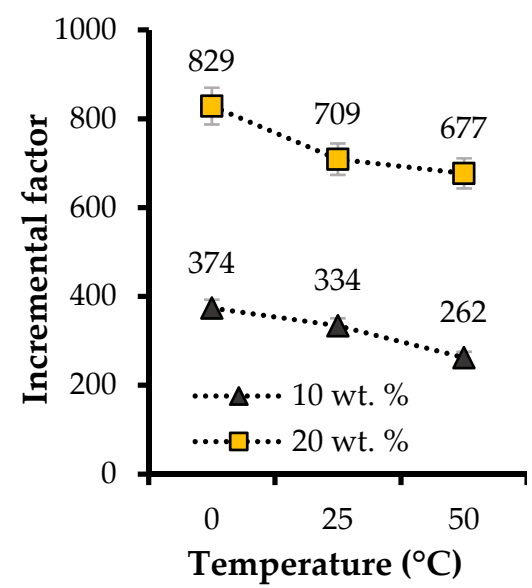

(f)

Figure 9. Adsorption isotherms of $\mathrm{CO}_{2}$ at high pressure $\left(3 \times 10^{-3}\right.$ up to $\left.3.0 \mathrm{MPa}\right)$ of CN.LYS2 at (a) $0{ }^{\circ} \mathrm{C}$, (b) $25{ }^{\circ} \mathrm{C}$, and (c) $50{ }^{\circ} \mathrm{C}$; (d) sandstone impregnated with a mass fraction of $10 \%$ at $50{ }^{\circ} \mathrm{C}$, (e) sandstone impregnated with a mass fraction of $20 \%$ at $50{ }^{\circ} \mathrm{C}$. (f) Relationship between the impregnation percentages (mass fractions of 10 and $20 \%$ ) and the adsorption capacity of $\mathrm{CO}_{2}$ at $3 \mathrm{MPa}$ and 0,25 , and $50{ }^{\circ} \mathrm{C}$.

To observe the pressure effect on the adsorption capacity of CN.LYS2, the $N_{\text {ads }}$ at atmospheric pressure and $0{ }^{\circ} \mathrm{C}\left(3.48 \mathrm{mmol} \mathrm{g}^{-1}\right)$ was compared to $N_{\text {ads }}$ at $3 \mathrm{MPa}$ and $0{ }^{\circ} \mathrm{C}\left(5.80 \mathrm{mmol} \mathrm{g}^{-1}\right)$. The increase of pressure produced an increase of $N_{\text {ads }}$ of $66.6 \%$, indicating physisorption as the main adsorption mechanism. At $50{ }^{\circ} \mathrm{C}$, as expected, the adsorption capacity decreased by $20 \%$ due to the exothermic character of adsorption. The obtained adsorption capacity is competitive compared to other results reported for nanomaterials under similar conditions $[43,44,58]$. The effect of pressure on the impregnated sandstone was also observed by comparing $N_{\text {ads }}$ at atmospheric pressure and $0{ }^{\circ} \mathrm{C}$ $\left(0.34 \mathrm{mmol} \mathrm{g}^{-1}\right.$ for SS-10 and $0.63 \mathrm{mmol} \mathrm{g}^{-1}$ for SS-20) to $N_{\text {ads }}$ at $3 \mathrm{MPa}$ and $0{ }^{\circ} \mathrm{C}\left(0.47 \mathrm{mmol} \mathrm{g}^{-1}\right.$ for SS-10 and $1.04 \mathrm{mmol} \mathrm{g}^{-1}$ for SS-20). The corresponding increases were $38.2 \%$ (SS-10) and $66.0 \%$ (SS-20), respectively. The maximum $N_{\text {ads }}$ under reservoir conditions was $0.85 \mathrm{mmol} \mathrm{g}^{-1}$ at a mass fraction of $20 \%$ of CN.LYS2.

Figure 9e presents incremental factors comparing $N_{\text {ads }}$ for sandstone without impregnation to $N_{\text {ads }}$ after impregnation with mass fractions of 10 and $20 \%$ at $3 \mathrm{MPa}$ and 0,25 , and $50{ }^{\circ} \mathrm{C}$. In the conditions of a shallow reservoir $\left(50^{\circ} \mathrm{C}\right.$ and $\left.3.0 \mathrm{MPa}\right)$, the incremental factor was 677 for SS-20. For the e-CCS process, the pressure could increase up 6.0 MPa so that $\mathrm{CO}_{2}$ is still in vapor phase, which allows a higher adsorbed amount. Appendix A presents the fit of the Sips and Toth models to the $\mathrm{CO}_{2}$ adsorption isotherms at high pressure and at 0,25 , and $50^{\circ} \mathrm{C}$ for CN.LYS2, SS-10, and SS-20 (Figures A1-A3, respectively). As expected, the Toth and Sips models led to very good fits: $\mathrm{R}^{2}>0.99$ for CN.LYS2, SS-10, and SS-20, and $\mathrm{R}^{2}>0.75$ for SS-10 at $0{ }^{\circ} \mathrm{C}$. In the latter case, the concavity of the isotherm was mainly due to the very rapid increase of the bulk density as a function of pressure with respect to the increase of the density of the adsorbed phase at pressure higher than $1.5 \mathrm{MPa}$.

Figure 10a presents the isosteric heat of adsorption $\left(Q_{\text {st }}\right)$ of CN.LYS2 and of sandstone impregnated with mass fractions of 10 and $20 \%$, as a function of $N_{\text {ads }}$ expressed in mmol per gram of total adsorbent material. $N_{\text {ads }}$ for SS-10 and SS-20 was small, and thus, Figure $10 \mathrm{~b}$ presents $Q_{\mathrm{st}}$ as a function of $N_{\text {ads }}$ in mmol per gram of carbon adsorbent material. The values of $Q_{\text {st }}$ varied from 25 to $33 \mathrm{~kJ} \mathrm{~mol}^{-1}$, which indicates a strong interaction in the adsorption system (high affinity). The interactions with the carbon porous structure could be increased by nitrogen-containing groups that are present onto the carbon surface. Nitrogen groups can indeed promote interactions between $\mathrm{CO}_{2}$ and the substrate. The values of $Q_{\mathrm{st}}$ compare favorably with those reported in the literature for different materials doped or not with nitrogen (20-25 kJ mol${ }^{-1}$, on average) [45,59-61]. 


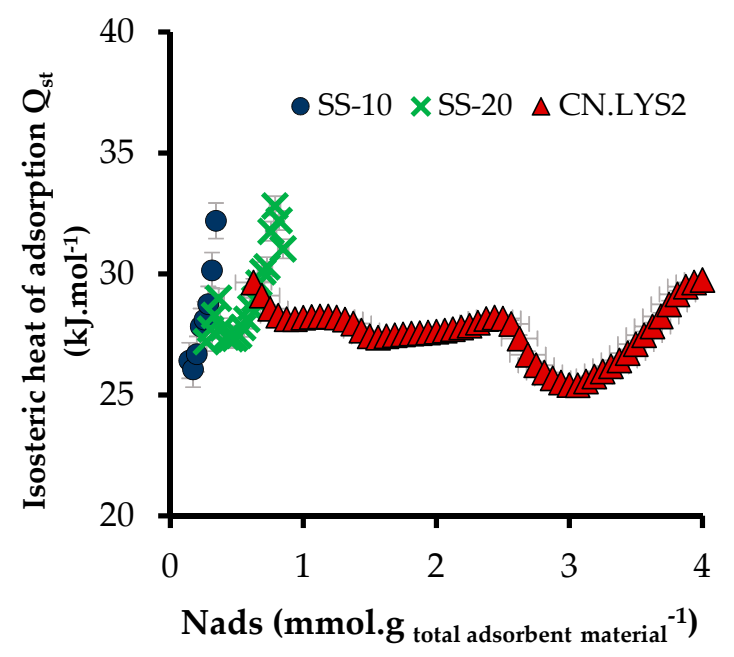

(a)

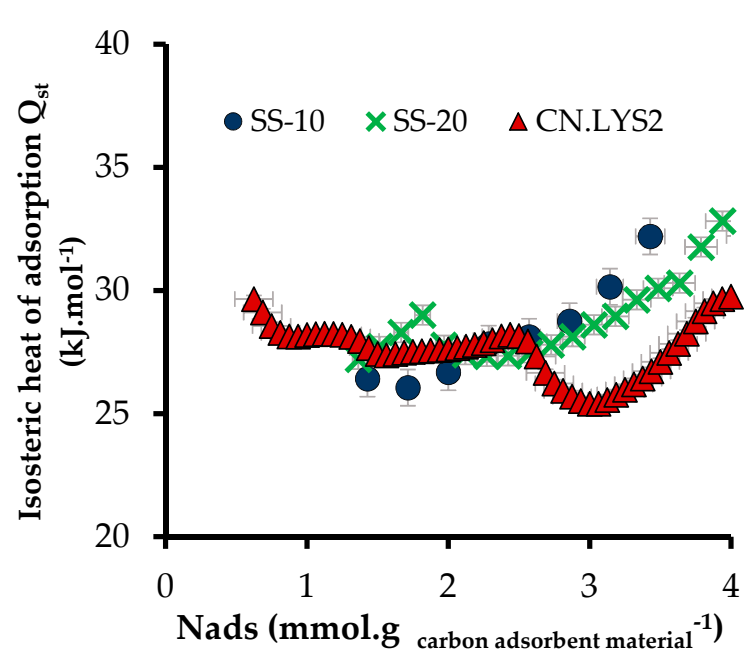

(b)

Figure 10. Isosteric heat of adsorption of CN.LYS2 and sandstone impregnated with mass fractions of 10 and $20 \%$, as a function of the adsorbed $\mathrm{CO}_{2}$ amount expressed: (a) in mmol per total amount of adsorbent material (sandstone and CN.LYS2) and (b) in mmol per amount of carbon adsorbent material.

The isosteric heat of adsorption of CN.LYS2 presented two distinct behaviors, whether $N_{\text {ads }}$ was either (i) lower or (ii) higher than $3 \mathrm{mmol} \mathrm{g}_{\text {carbonadsorbentmaterial }}{ }^{-1}$. For case (i), $Q_{\text {st }}$ decreased with $N_{\text {ads }}$ due to the increasing distance between the last adsorbed layer and the carbon surface, thus decreasing the molecular interactions (Figure 10b). For case (ii), i.e., when $N_{\text {ads }}$ was higher than $3 \mathrm{mmol}_{\text {carbonadsorbentmaterial }}{ }^{-1}, Q_{\text {st }}$ increased due to the increased interactions between adsorbate molecules [61]. For SS-10 and SS-20, the value of $Q_{\text {st }}$ also increased with $N_{\text {ads }}$. Because the interactions between sandstone (silica) and $\mathrm{CO}_{2}$ were weak and because the contribution of the surface area associated to the carbon material was lower than for CN.LYS2 alone, it can be assumed again that the interactions between the adsorbed gas layers prevailed [61].

\subsection{2. $\mathrm{CO}_{2}$ and $\mathrm{N}_{2}$ Adsorption at High Pressure-Gravimetric Measurement Method}

Using the PyIAST application and using the pure-components adsorption isotherms obtained by experimental tests, it is possible to characterize the behavior of each component and to predict the adsorbed amount of each component present in a mixture [56]. It is, thus, possible to obtain the adsorbed amount at a constant temperature by varying the concentration of the components (at constant pressure) or the pressure (at constant concentrations). Initially, it is necessary to use the "isothermal interpolator" to generate data points that follow a given isothermal model, avoiding the search for an appropriate analytical model and examining the quality of its fit to the data (i.e., Langmuir, Freundlich or Toth, among others) [56]. The isothermal interpolator is a tool included in the PyIAST package. After that, PyIAST takes the interpolated data for its calculations. Calculations are done using a predesigned routine [56].

In the present case, the experimental data of each pure component $\left(\mathrm{CO}_{2}\right.$ and $\left.\mathrm{N}_{2}\right)$ were obtained by HP-TGA at $50{ }^{\circ} \mathrm{C}$, between 0.1 and $2.5 \mathrm{MPa}$, and with a flow of $\mathrm{CO}_{2}$ or $\mathrm{N}_{2}\left(50 \mathrm{~mL} \mathrm{~min}^{-1}\right.$ up to 1.0 $\mathrm{MPa}$ and $70 \mathrm{~mL} \mathrm{m^{-1 }}$ up to $2.5 \mathrm{MPa}$ ). The prediction was calculated at $50{ }^{\circ} \mathrm{C}$ by varying: (1) the system pressure from 0.1 to $2.5 \mathrm{MPa}$ at constant $\mathrm{CO}_{2}$ concentration of $20 \%$ and (2) the concentration of $\mathrm{CO}_{2}$, from 5 to $100 \%$ at a constant pressure of $2.5 \mathrm{MPa}$. The evaluated materials were CN.LYS2 and sandstone from a real reservoir (RS) impregnated with a mass fraction of $20 \%$ of CN.LYS2. It is important to mention that it might be possible to obtain considerable adsorbed quantities for a cleaning and adsorption balance of more than 12-24 h, because the nanomaterials (main adsorbent) are micro/mesoporous. A longer cleaning time thus allows eliminating adsorbed gases and moisture. In the same way, an adequate equilibrium time allows for greater diffusion of the gas into the porous 
structure and greater interactions with the material, which would allow a higher adsorbed amount. Therefore, to analyze the selectivity, a shorter time was used (cleaning and adsorption equilibrium time of $2 \mathrm{~h}$ at each pressure).

It was not possible to obtain the $\mathrm{CO}_{2}$ isotherm for RS because the latter had a too low surface area, so the maximum value for RS at $50^{\circ} \mathrm{C}$ and $2.5 \mathrm{MPa}$ was $0.033 \mathrm{mmol} \mathrm{g}^{-1}$. For RS, the adsorbed amount of $\mathrm{N}_{2}$ was $3.19 \mathrm{mmol} \mathrm{g}-1$ at $50{ }^{\circ} \mathrm{C}$ and $2.5 \mathrm{MPa}$. Figure $11 \mathrm{a}$,b present the $\mathrm{CO}_{2}$ and $\mathrm{N}_{2}$ adsorption isotherms under continuous gas flow for CN.LYS2 and RS-20. The increment factor of $N_{\text {ads }}$ for RS-20 with respect to RS was $19\left(0.66 \mathrm{mmol} \mathrm{g}^{-1}\right.$ at $50{ }^{\circ} \mathrm{C}$ and $\left.2.5 \mathrm{MPa}\right)$. In addition, the theoretical value of $N_{\text {ads }}$ for RS with a mass fraction of $20 \%$ of CN.LYS was $0.78 \mathrm{mmol} \mathrm{g}^{-1}$ but the experimental value was $0.66 \mathrm{mmol} \mathrm{g}^{-1}$ (i.e., $85 \%$ of the theoretical one).

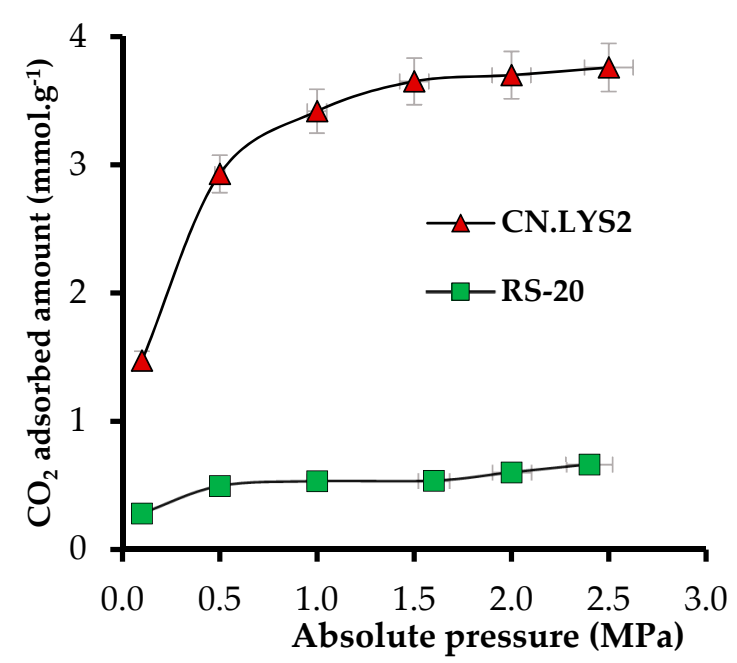

(a)

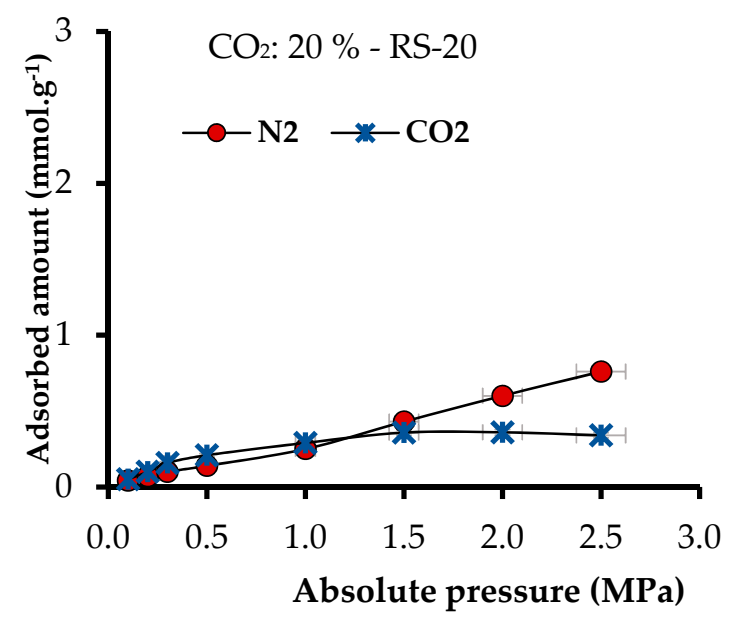

(c)

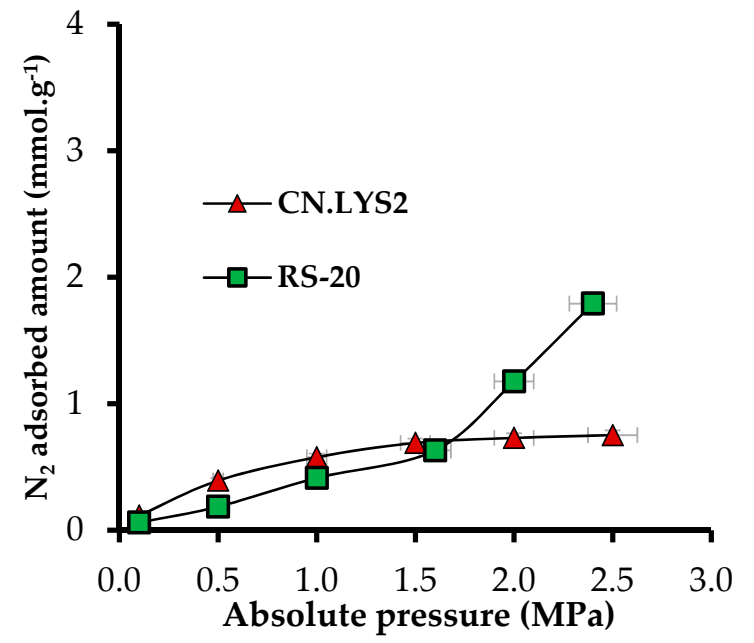

(b)

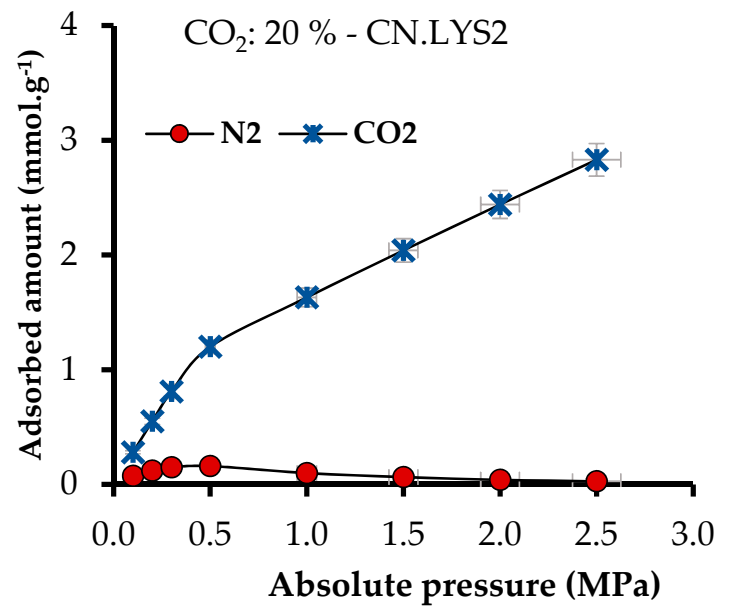

(d)

Figure 11. Cont. 


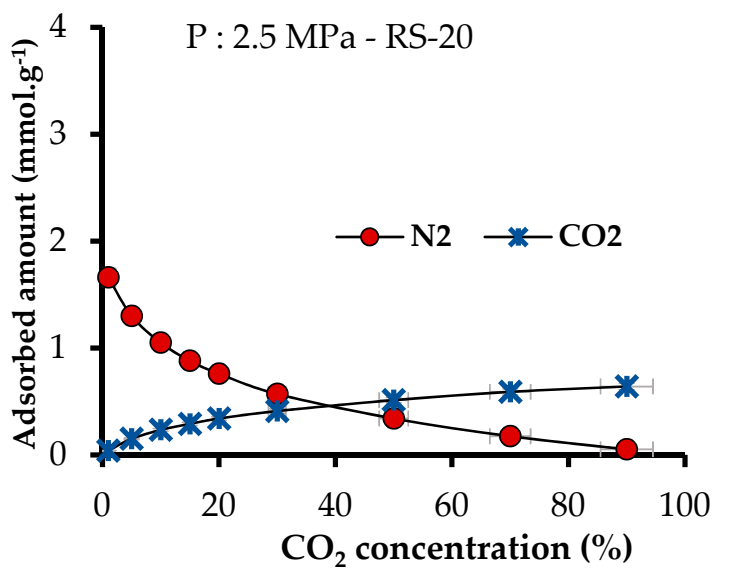

(e)

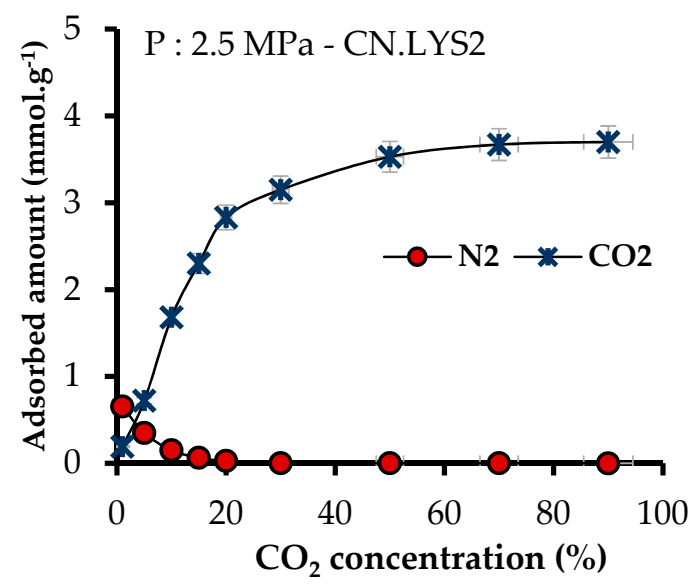

(f)

Figure 11. Adsorption isotherm of CN.LYS2 and RS-20 at $50{ }^{\circ} \mathrm{C}$ between 0.1 and $2.5 \mathrm{MPa}$ for (a) pure $\mathrm{CO}_{2}$ and (b) pure $\mathrm{N}_{2}$. Adsorption isotherm simulating a $\mathrm{N}_{2} / \mathrm{CO}_{2}$ mixture at $50{ }^{\circ} \mathrm{C}$, constant $\mathrm{CO}_{2}$ concentration of $20 \%$ and varying the pressure for (c) RS-20 and (d) CN.LYS2; and varying the $\mathrm{CO}_{2}$ concentration at constant pressure of 2.5 MPa for (e) RS-20 and (f) CN.LYS2.

Figure 11c, d present the simulated adsorbed amount for a $\mathrm{N}_{2} / \mathrm{CO}_{2}$ mixture at constant $\mathrm{CO}_{2}$ concentration of $20 \%$ and at $50{ }^{\circ} \mathrm{C}$ by varying the pressure for RS-20 and CN.LYS2, respectively. For RS-20, the affinity for $\mathrm{CO}_{2}$ was higher $(\mathrm{P}<1 \mathrm{MPa})$ compared to RS without impregnation, but the $\mathrm{N}_{\text {ads }}$ for $\mathrm{N}_{2}$ was superior (123.5\%) to that for $\mathrm{CO}_{2}$ (Figure 11c). For RS-20, the $\mathrm{CO}_{2}$ isotherm obtained a form that would be impossible to obtain without impregnation due to the lack of surface area and molecular interactions. The isotherm for CN.LYS2 showed a higher affinity for $\mathrm{CO}_{2}$ and a correspondingly higher $N_{\text {ads }}$ than for $\mathrm{N}_{2}$, which, above $0.5 \mathrm{MPa}$, decreased considerably (Figure 11d). Similar conditions occurred when the $\mathrm{CO}_{2}$ concentration was varied at $2.5 \mathrm{MPa}$ and $50^{\circ} \mathrm{C}$ (Figure $11 \mathrm{e}, \mathrm{f}$ ), CN.LYS2 had more affinity for $\mathrm{CO}_{2}$ than RS-20, and CN.LYS2 had a considerably higher $\mathrm{N}_{\text {ads }}$ for $\mathrm{CO}_{2}$ than for $\mathrm{N}_{2}$. Figure 11e shows the increment of $\mathrm{N}_{\text {ads }}$ only for $\mathrm{CO}_{2}$ while the $\mathrm{CO}_{2}$ concentration was increased in RS-20; at low concentrations of $\mathrm{CO}_{2}(<30 \%)$, the $\mathrm{N}_{\text {ads }}$ for $\mathrm{N}_{2}$ was higher. For CN.LYS2 at low concentrations of $\mathrm{CO}_{2}(1 \%)$, the slope increment was significant, indicating a higher affinity for $\mathrm{CO}_{2}$ at low concentrations.

From Figure 11, it can be concluded that the pyIAST is a useful tool because it is possible to simulate the behavior of adsorption systems from some pure gas adsorption data.

\section{Conclusions}

To the best of our knowledge, this is the first study using nanoparticles to modify the $\mathrm{CO}_{2}$ adsorption capacities of a reservoir in a carbon capture and storage (CCS) process. Moreover, this is the first research proposing a possible new configuration of the CCS process in which the storage is performed in shallow reservoirs (less than $300 \mathrm{~m}$ ). We called it enhanced CCS (e-CCS), for which the main advantage is that the $\mathrm{CO}_{2}$ capture/separation step is removed, and the flue gas is injected directly into shallow deposits, where the $\mathrm{CO}_{2}$ is gaseous and where the adsorption phenomena control capture and storage.

Nitrogen-rich carbon nanospheres allowed increasing the adsorption capacity by $67,700 \%$ with a mass fraction of only $20 \%$ under realistic reservoir conditions $\left(50{ }^{\circ} \mathrm{C}\right.$ and $3 \mathrm{MPa}$ ). This was possible thanks to the higher surface area and to the favorable chemical composition, which promoted the capture and storage of $\mathrm{CO}_{2}$. These $\mathrm{N}$-doped carbon nanospheres, synthesized by a simple process, had competitive $\mathrm{CO}_{2}$ capture performances compared to other special materials reported in the literature. Therefore, this research opens an interesting line of research that would expand knowledge in the field of carbon nanospheres for application in the adsorption and geological storage of $\mathrm{CO}_{2}$. 
Author Contributions: Conceptualization, F.B.C., C.A.F., F.C.-M., V.F., A.C., A.C.M. and E.R.A.; methodology, F.B.C., C.A.F., F.C.-M., V.F. and E.R.A.; software, F.B.C., E.R.A.; validation, F.B.C., F.C.-M., V.F., S.S. and E.R.A.; formal analysis, F.B.C., C.A.F., F.C.-M., V.F., A.C., S.S. and E.R.A.; investigation, S.S. and E.R.A.; resources, F.B.C., C.A.F., F.C.-M., A.F.P.-C., V.F., A.C., S.S., A.C.M. and E.R.A.; Writing-Original Draft preparation, E.R.A.; Writing-Review and Editing, F.B.C., C.A.F., F.C.-M., A.F.P.-C., V.F., A.C., S.S. and E.R.A.; visualization, E.R.A.; supervision, F.B.C., F.C.-M., and V.F.

Funding: The authors thank COLCIENCIAS for financing the doctoral studies of Elizabeth Rodriguez Acevedo through the call 647-2014. The authors thank COLCIENCIAS, Agencia Nacional de Hidrocarburos-ANH provided by agreement 272-2017 for the support provided and Universidad Nacional de Colombia for the support provided in the agreement 272-2017. The authors thank to Spanish Ministry of Science, Innovation and Universities, FEDER funds, contract number RTI2018-099224-B-I00. The authors also thank to ERASMUS+ program (agreement F NANCY43) and ENLAZAMUNDOS-SAPIENCIA for the support of academic internships. French authors acknowledge FEDER funds, through TALiSMAN project, for the financial support.

Acknowledgments: The authors thank the Universidad Nacional de Colombia, the University of Granada, and the University of Lorraine-Institut Jean Lamour for their logistical and financial support. The authors also thank Philippe Gadonneix and Saray Perez-Robles for their technical support in the experimental tests.

Conflicts of Interest: The authors declare no conflict of interest.

\section{Appendix A}

This section presents the adsorption isotherms fitted by the Sips and Toth models, for $\mathrm{CO}_{2}$ at high pressure and 0,25 , and $50^{\circ} \mathrm{C}$. This information is related to Section 3.2.1. Pure $\mathrm{CO}_{2}$ adsorption at high pressure-Manometric measurement method.

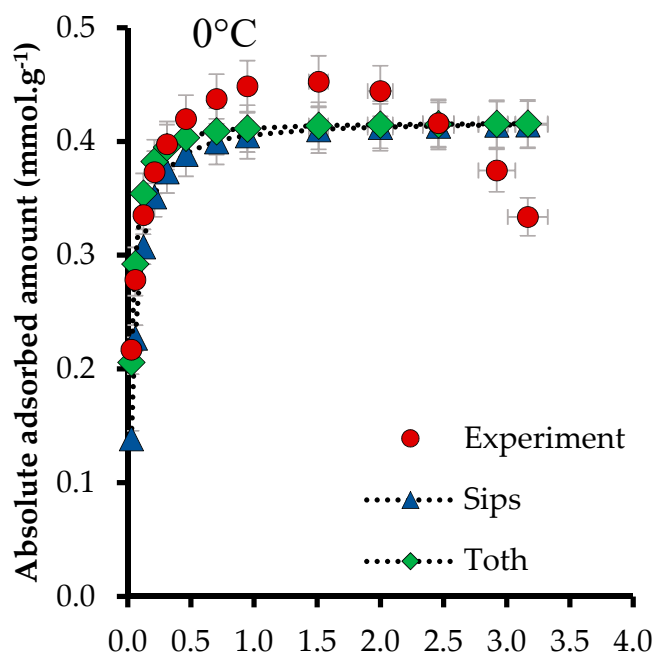

Absolute pressure (MPa)

(a)

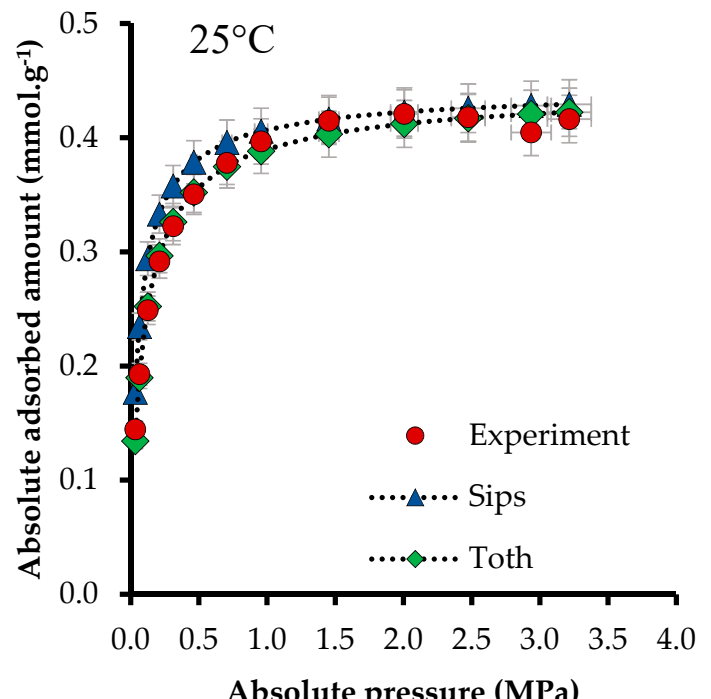

Absolute pressure (MPa)

(b)

Figure A1. Cont. 


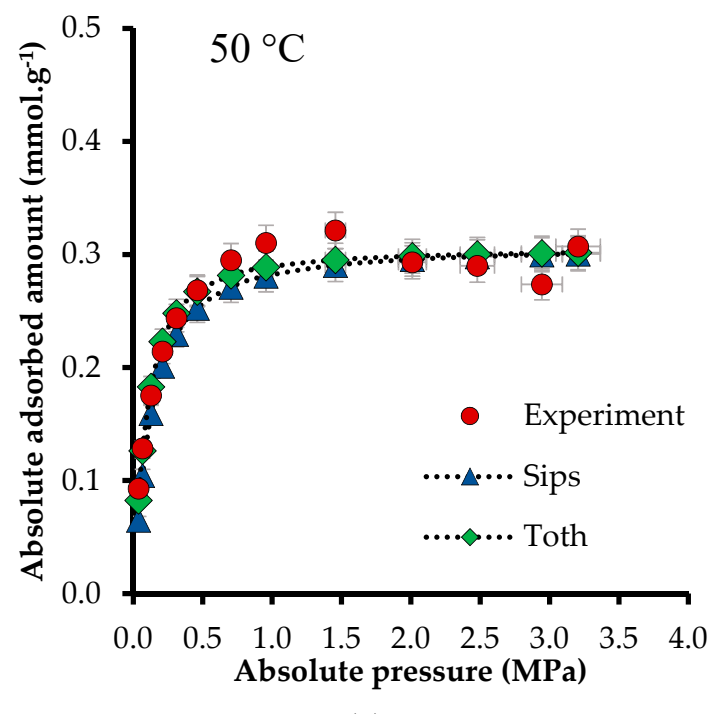

(c)

Figure A1. Adsorption isotherms fitted by the Sips and Toth models for sandstone impregnated with a mass fraction of $10 \%$ of carbon nanospheres synthesized with L-Lysine (CN.LYS2) at (a) $0^{\circ} \mathrm{C},(\mathbf{b}) 25^{\circ} \mathrm{C}$, and (c) $50{ }^{\circ} \mathrm{C}$.

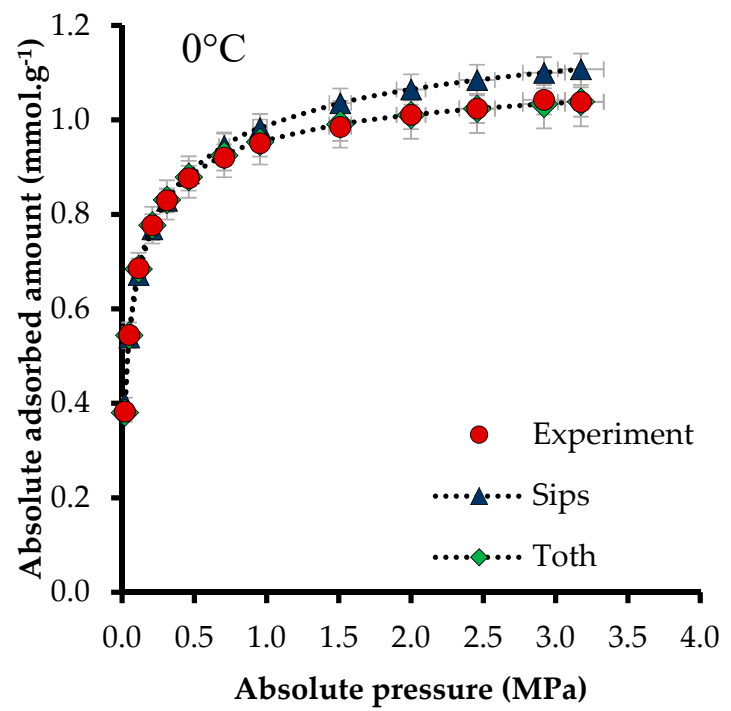

(a)

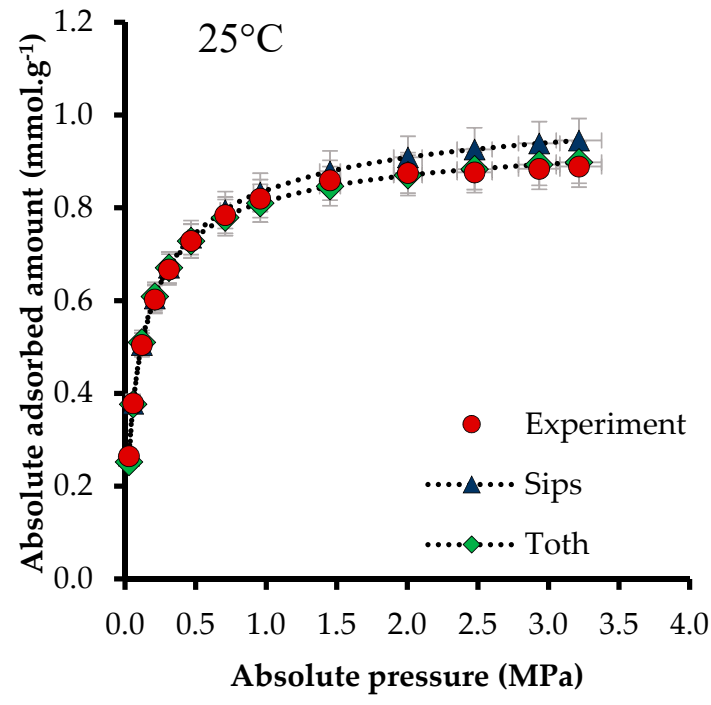

(b)

Figure A2. Cont. 


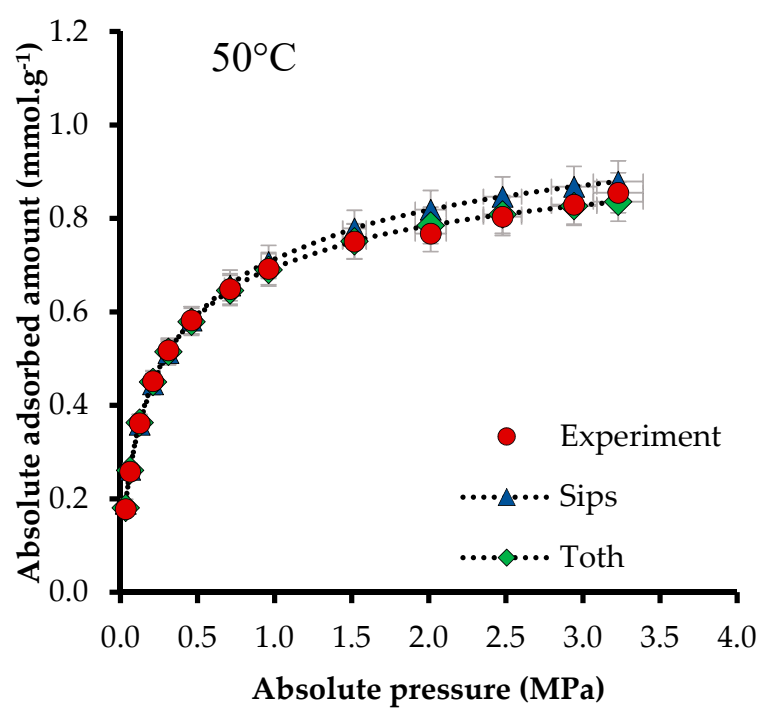

(c)

Figure A2. Adsorption isotherms fitted the Sips and Toth models for sandstone impregnated with a mass fraction of $20 \%$ of carbon nanospheres synthesized with L-Lysine (CN.LYS2) at (a) $0{ }^{\circ} \mathrm{C},(\mathbf{b}) 25^{\circ} \mathrm{C}$, and (c) $50{ }^{\circ} \mathrm{C}$.

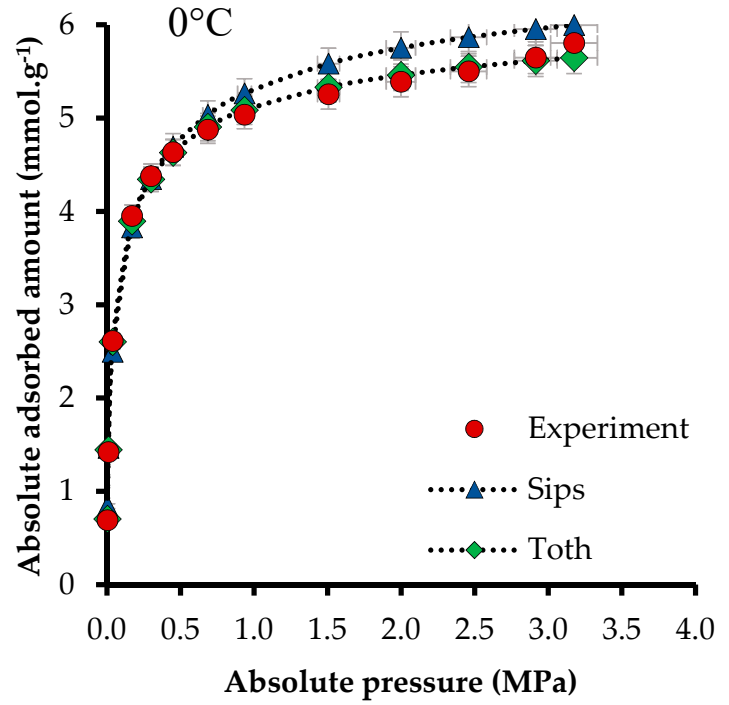

(a)

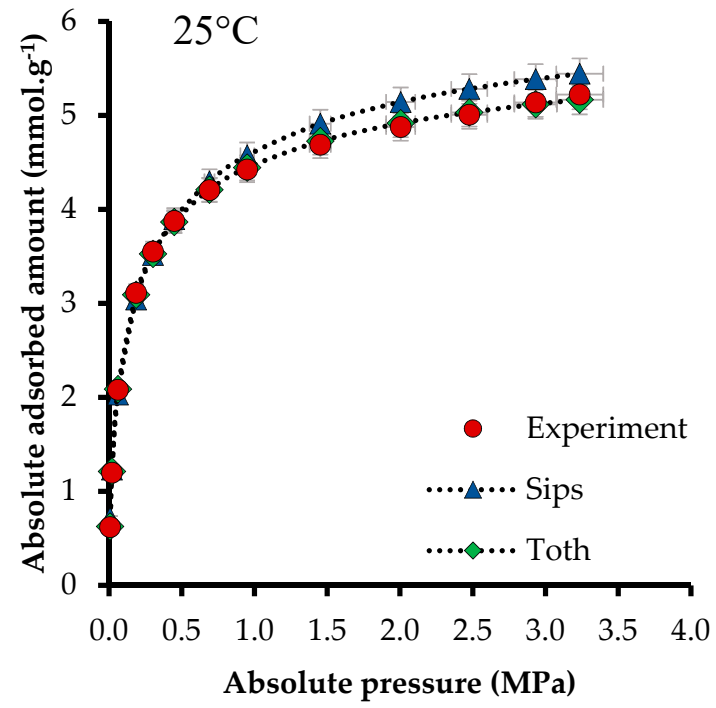

(b)

Figure A3. Cont. 


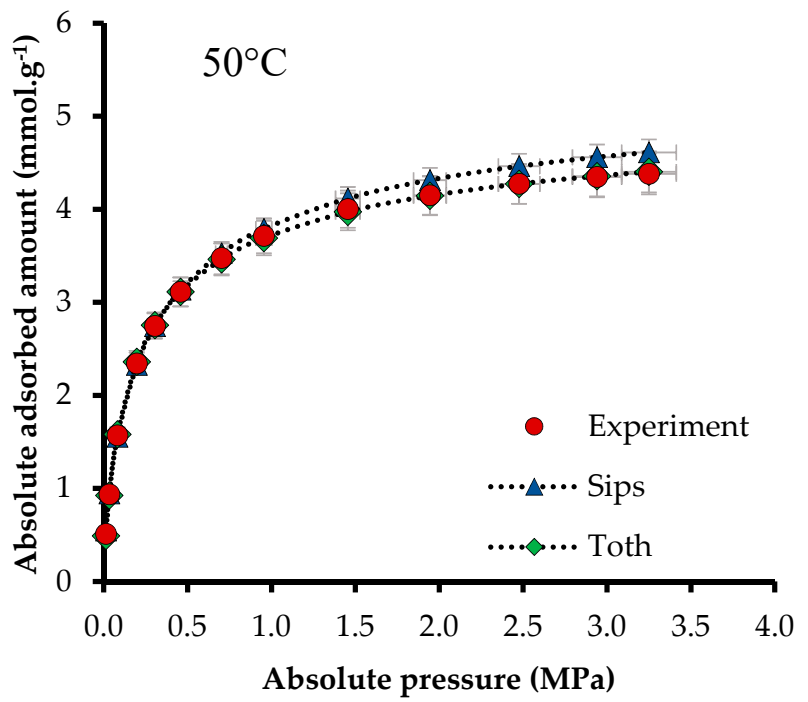

(c)

Figure A3. Adsorption isotherms fitted by the Sips and Toth models for carbon nanospheres synthesized with L-lysine (CN.LYS2) at (a) $0{ }^{\circ} \mathrm{C}$, (b) $25^{\circ} \mathrm{C}$, and (c) $50{ }^{\circ} \mathrm{C}$.

\section{References}

1. Root, T.L.; Price, J.T.; Hall, K.R.; Schneider, S.H.; Rosenzweig, C.; Pounds, J.A. Fingerprints of global warming on wild animals and plants. Nature 2003, 421, 57. [CrossRef]

2. Vitousek, P.M. Beyond global warming: Ecology and global change. Ecology 1994, 75, 1861-1876. [CrossRef]

3. McGlade, C.; Ekins, P. The geographical distribution of fossil fuels unused when limiting global warming to 2 C. Nature 2015, 517, 187. [CrossRef]

4. Harvey, L.D. Global Warming; Routledge: Abingdon, UK, 2018.

5. Baer, H.; Singer, M. Global Warming and the Political Ecology of Health: Emerging Crises and Systemic Solutions; Routledge: Abingdon, UK, 2016.

6. Lashof, D.A.; Ahuja, D.R. Relative contributions of greenhouse gas emissions to global warming. Nature 1990, 344, 529. [CrossRef]

7. Anderson, T.R.; Hawkins, E.; Jones, P.D. $\mathrm{CO}_{2}$, the greenhouse effect and global warming: From the pioneering work of Arrhenius and Callendar to today's Earth System Models. Endeavour 2016, 40, 178-187. [CrossRef]

8. US-EPA, E.P.A. Global Greenhouse Gas Emissions Data. 2019. Available online: https://www.epa.gov/ ghgemissions/global-greenhouse-gas-emissions-data (accessed on 15 May 2019).

9. Edenhofer, O.; Pichs-Madruga, R.; Sokona, Y.; Minx, J.C.; Farahani, E.; Kadner, S.; Seyboth, K.; Adler, A.; Baum, I.; Brunner, S.; et al. Climate Change 2014, Mitigation of Climate Change. In Contribution of Working Group III to the Fifth Assessment Report of the Intergovernmental Panel on Climate Change; IPCC, 2014: Summary for Policymakers; Cambridge University Press: Cambridge, UK, 2014.

10. Tan, Y.; Nookuea, W.; Li, H.; Thorin, E.; Yan, J. Property impacts on Carbon Capture and Storage (CCS) processes: A review. Energy Convers. Manag. 2016, 118, 204-222. [CrossRef]

11. Change, N.G.C. Vital Signs of the Planet; Earth Science Communications Team at NASA's Jet Propulsion Laboratory: Pasadena, CA, USA, 2018; p. 30.

12. NASA. Global Climate Change. Vital Signs of the Planet. 2019. Available online: https://climate.nasa.gov/ vital-signs/carbon-dioxide/ (accessed on 30 March 2019).

13. Norby, R.J.; Luo, Y. Evaluating ecosystem responses to rising atmospheric $\mathrm{CO}_{2}$ and global warming in a multi-factor world. New Phytol. 2004, 162, 281-293. [CrossRef]

14. Halmann, M.M. Chemical Fixation of Carbon DioxideMethods for Recycling $\mathrm{CO}_{2}$ into Useful Products; CRC Press: Boca Raton, FL, USA, 2018.

15. Cox, P.M.; Betts, R.A.; Jones, C.D.; Spall, S.A.; Totterdell, I.J. erratum: Acceleration of global warming due to carbon-cycle feedbacks in a coupled climate model. Nature 2000, 408, 750. [CrossRef] 
16. Wang, J.; Huang, L.; Yang, R.; Zhang, Z.; Wu, J.; Gao, Y.; Wang, Q.; O'Hare, D.; Zhong, Z. Recent advances in solid sorbents for $\mathrm{CO}_{2}$ capture and new development trends. Energy Environ. Sci. 2014, 7, 3478-3518. [CrossRef]

17. Conti, J.; Holtberg, P.; Diefenderfer, J.; LaRose, A.; Turnure, J.T.; Westfall, L. International Energy Outlook 2016 with Projections to 2040; USDOE Energy Information Administration (EIA): Washington, DC, USA, 2016.

18. Metz, B.; Davidson, O.; de Coninck, H. Carbon Dioxide Capture and Storage: Special Report of the Intergovernmental Panel on Climate Change; Cambridge University Press: Cambridge, UK, 2005.

19. Kang, S.-P.; Lee, H. Recovery of $\mathrm{CO}_{2}$ from flue gas using gas hydrate: Thermodynamic verification through phase equilibrium measurements. Environ. Sci. Technol. 2000, 34, 4397-4400. [CrossRef]

20. Yang, Q.; Xue, C.; Zhong, C.; Chen, J.F. Molecular simulation of separation of $\mathrm{CO}_{2}$ from flue gases in CU-BTC metal-organic framework. AIChE J. 2007, 53, 2832-2840. [CrossRef]

21. Song, C.; Pan, W.; Srimat, S.T.; Zheng, J.; Li, Y.; Wang, Y.H.; Xu, B.O.; Zhu, Q.M. Tri-reforming of methane over Ni catalysts for $\mathrm{CO}_{2}$ conversion to Syngas with desired $\mathrm{H}_{2} \mathrm{CO}$ ratios using flue gas of power plants without $\mathrm{CO}_{2}$ separation. Stud. Surf. Sci. Catal. 2004, 153, 315-322.

22. Bui, M.; Adjiman, C.S.; Bardow, A.; Anthony, E.J.; Boston, A.; Brown, S.; Fennell, P.S.; Fuss, S.; Galindo, A.; Hackett, L.A.; et al. Carbon capture and storage (CCS): The way forward. Energy Environ. Sci. 2018, 11, 1062-1176. [CrossRef]

23. Knorr, W. Is the airborne fraction of anthropogenic $\mathrm{CO}_{2}$ emissions increasing? Geophys. Res. Lett. $2009,36$. [CrossRef]

24. Cook, P.; Causebrook, R.; Gale, J.; Michel, K.; Watson, M. What have we learned from small-scale injection projects? Energy Procedia 2014, 63, 6129-6140. [CrossRef]

25. IEA, I. World Energy Outlook 2011; International Energy Agency: Paris, France, 2011; p. 666.

26. Balat, H.; Öz, C. Technical and Economic Aspects of Carbon Capture an Storage-A Review. Energy Explor. Exploit. 2007, 25, 357-392. [CrossRef]

27. Gough, C. State of the art in carbon dioxide capture and storage in the UK: An experts' review. Int. J. Greenh. Gas Control 2008, 2, 155-168. [CrossRef]

28. Gough, C. Carbon Capture and Its Storage: An Integrated Assessment; Routledge: Abingdon, UK, 2016.

29. Bailon-García, E.P.C.; Agustín, F.; Elizabeth, R.A.; Francisco, C.M. Nanoparticle Fabrication Methods. In Formation Damage in Oil and Gas Reservoirs. Nanotechnology Applications for Its Inhibition/Remediation; Franco, C.A.a.C.C., Farid, B., Eds.; Nova Science Publishers: Hauppauge, NY, USA, 2018; pp. 69-150.

30. Franco, C.A.C.C.; Farid, B. Formation Damage in Oil and Gas Reservoirs. Nanotechnology Applications for Its Inhibition/Remediation; Nova Science Publishers: Hauppauge, NY, USA, 2018.

31. Franco, C.A.; Zabala, R.; Cortés, F.B. Nanotechnology applied to the enhancement of oil and gas productivity and recovery of Colombian fields. J. Pet. Sci. Eng. 2017, 157, 39-55. [CrossRef]

32. Franco, C.A.; Nassar, N.N.; Ruiz, M.A.; Pereira-Almao, P.; Cortés, F.B. Nanoparticles for inhibition of asphaltenes damage: Adsorption study and displacement test on porous media. Energy Fuels 2013, 27, 2899-2907. [CrossRef]

33. Moncayo-Riascos, I.; Franco, C.A.; Cortés, F.B. Dynamic Molecular Modeling and Experimental Approach of Fluorocarbon Surfactant-Functionalized $\mathrm{SiO}_{2}$ Nanoparticles for Gas-Wettability Alteration on Sandstones. J. Chem. Eng. Data 2019, 64, 1860-1872. [CrossRef]

34. Hurtado, Y.; Beltrán, C.; Zabala, R.D.; Lopera, S.H.; Franco, C.A.; Nassar, N.N.; Cortés, F.B. Effects of Surface Acidity and Polarity of $\mathrm{SiO}_{2}$ Nanoparticles on the Foam Stabilization Applied to Natural Gas Flooding in Tight Gas-Condensate Reservoirs. Energy Fuels 2018, 32, 5824-5833. [CrossRef]

35. Cardona, L.; Arias-Madrid, D.; Cortés, F.; Lopera, S.; Franco, C. Heavy oil upgrading and enhanced recovery in a steam injection process assisted by $\mathrm{NiO}$-and $\mathrm{PdO}$-Functionalized $\mathrm{SiO}_{2}$ nanoparticulated catalysts. Catalysts 2018, 8, 132. [CrossRef]

36. Yang, D.; Wang, S.; Zhang, Y. Analysis of $\mathrm{CO}_{2}$ migration during nanofluid-based supercritical $\mathrm{CO}_{2}$ geological storage in saline aquifers. Aerosol Air Qual. Res. 2014, 14, 1411-1417. [CrossRef]

37. Silvestre-Albero, J.; Reinoso, F.R. Nuevos materiales de carbón para la captura de $\mathrm{CO}_{2}$. Boletín del Grupo Español del Carbón 2012, 24, 2-6.

38. Zhang, X.Q.; Li, W.C.; Lu, A.H. Designed porous carbon materials for efficient $\mathrm{CO}_{2}$ adsorption and separation. New Carbon Mater. 2015, 30, 481-501. [CrossRef] 
39. Bandosz, T.J.; Seredych, M.; Rodríguez-Castellón, E.; Cheng, Y.; Daemen, L.L.; Ramírez-Cuesta, A.J. Evidence for $\mathrm{CO}_{2}$ reactive adsorption on nanoporous $\mathrm{S}$-and $\mathrm{N}$-doped carbon at ambient conditions. Carbon 2016, 96 , 856-863. [CrossRef]

40. Lithoxoos, G.P.; Labropoulos, A.; Peristeras, L.D.; Kanellopoulos, N.; Samios, J.; Economou, I.G. Adsorption of $\mathrm{N}_{2}, \mathrm{CH}_{4}, \mathrm{CO}$ and $\mathrm{CO}_{2}$ gases in single walled carbon nanotubes: A combined experimental and Monte Carlo molecular simulation study. J. Supercrit. Fluids 2010, 55, 510-523. [CrossRef]

41. Bikshapathi, M.; Sharma, A.; Sharma, A.; Verma, N. Preparation of carbon molecular sieves from carbon micro and nanofibers for sequestration of $\mathrm{CO}_{2}$. Chem. Eng. Res. Des. 2011, 89, 1737-1746. [CrossRef]

42. Chowdhury, S.; Balasubramanian, R. Highly efficient, rapid and selective $\mathrm{CO}_{2}$ capture by thermally treated graphene nanosheets. J. CO2 Util. 2016, 13, 50-60. [CrossRef]

43. Alonso, A.; Moral-Vico, J.; Markeb, A.A.; Busquets-Fité, M.; Komilis, D.; Puntes, V.; Sánchez, A.; Font, X. Critical review of existing nanomaterial adsorbents to capture carbon dioxide and methane. Sci. Total Environ. 2017, 595, 51-62. [CrossRef]

44. Ma, Y.; Wang, Z.; Xu, X.; Wang, J. Review on porous nanomaterials for adsorption and photocatalytic conversion of $\mathrm{CO}_{2}$. Chin. J. Catal. 2017, 38, 1956-1969. [CrossRef]

45. Babu, D.J.; Bruns, M.; Schneider, R.; Gerthsen, D.; Schneider, J.J. Understanding the influence of N-doping on the $\mathrm{CO}_{2}$ adsorption characteristics in carbon nanomaterials. J. Phys. Chem. C 2017, 121, 616-626. [CrossRef]

46. Chen, A.; Li, S.; Yu, Y.; Liu, L.; Li, Y.; Wang, Y.; Xia, K. Self-catalyzed strategy to form hollow carbon nanospheres for $\mathrm{CO}_{2}$ capture. Mater. Lett. 2016, 185, 63-66. [CrossRef]

47. Heydari-Gorji, A.; Belmabkhout, Y.; Sayari, A. Degradation of amine-supported $\mathrm{CO}_{2}$ adsorbents in the presence of oxygen-containing gases. Microporous Mesoporous Mater. 2011, 145, 146-149. [CrossRef]

48. Dong, Y.-R.; Nishiyama, N.; Egashira, Y.; Ueyama, K. Basic Amid Acid-Assisted Synthesis of Resorcinol-Formaldehyde Polymer and Carbon Nanospheres. Ind. Eng. Chem. Res. 2008, 47, 4712-4716. [CrossRef]

49. Bai, X.; Li, J.; Cao, C.; Hussain, S. Solvothermal synthesis of the special shape (deformable) hollow g- $\mathrm{C}_{3} \mathrm{~N}_{4}$ nanospheres. Mater. Lett. 2011, 65, 1101-1104. [CrossRef]

50. Franco-Aguirre, M.; Zabala, R.D.; Lopera, S.H.; Franco, C.A.; Cortés, F.B. Interaction of anionic surfactant-nanoparticles for gas-Wettability alteration of sandstone in tight gas-condensate reservoirs. J. Nat. Gas Sci. Eng. 2018, 51, 53-64. [CrossRef]

51. Schaefer, S.; Fierro, V.; Izquierdo, M.T.; Celzard, A. Assessment of hydrogen storage in activated carbons produced from hydrothermally treated organic materials. Int. J. Hydrog. Energy 2016, 41, 12146-12156. [CrossRef]

52. Schaefer, S.; Fierro, V.; Szczurek, A.; Izquierdo, M.T.; Celzard, A. Physisorption, chemisorption and spill-over contributions to hydrogen storage. Int. J. Hydrog. Energy 2016, 41, 17442-17452. [CrossRef]

53. Tzabar, N.; Brake, H.T. Adsorption isotherms and Sips models of nitrogen, methane, ethane, and propane on commercial activated carbons and polyvinylidene chloride. Adsorption 2016, 22, 901-914. [CrossRef]

54. Álvarez-Gutiérrez, N.; Gil, M.V.; Rubiera, F.; Pevida, C. Adsorption performance indicators for the $\mathrm{CO}_{2} / \mathrm{CH}_{4}$ separation: Application to biomass-based activated carbons. Fuel Process. Technol. 2016, 142, 361-369. [CrossRef]

55. Abdeljaoued, A.; Querejeta, N.; Durán, I.; Álvarez-Gutiérrez, N.; Pevida, C.; Chahbani, M. Preparation and Evaluation of a Coconut Shell-Based Activated Carbon for $\mathrm{CO}_{2} / \mathrm{CH}_{4}$ Separation. Energies 2018, 11, 1748. [CrossRef]

56. Simon, C.M.; Smit, B.; Haranczyk, M. pyIAST: Ideal adsorbed solution theory (IAST) Python package. Comput. Phys. Commun. 2016, 200, 364-380. [CrossRef]

57. Cavenati, S.; Grande, C.A.; Rodrigues, A.E. Adsorption equilibrium of methane, carbon dioxide, and nitrogen on zeolite 13X at high pressures. J. Chem. Eng. Data 2004, 49, 1095-1101. [CrossRef]

58. Himeno, S.; Tomita, T.; Suzuki, K.; Yoshida, S. Characterization and selectivity for methane and carbon dioxide adsorption on the all-silica DD3R zeolite. Microporous Mesoporous Mater. 2007, 98, 62-69. [CrossRef]

59. Dunne, J.; Mariwala, R.; Rao, M.; Sircar, S.; Gorte, R.J.; Myers, A.L. Calorimetric heats of adsorption and adsorption isotherms. 1. $\mathrm{O}_{2}, \mathrm{~N}_{2}, \mathrm{Ar}, \mathrm{CO}_{2}, \mathrm{CH}_{4}, \mathrm{C}_{2} \mathrm{H}_{6}$, and SF6 on silicalite. Langmuir 1996, 12, 5888-5895. [CrossRef]

60. Siriwardane, R.V.; Shen, M.S.; Fisher, E.P.; Poston, J.A. Adsorption of $\mathrm{CO}_{2}$ on molecular sieves and activated carbon. Energy Fuels 2001, 15, 279-284. [CrossRef] 
61. Himeno, S.; Komatsu, T.; Fujita, S. High-pressure adsorption equilibria of methane and carbon dioxide on several activated carbons. J. Chem. Eng. Data 2005, 50, 369-376. [CrossRef]

(C) 2019 by the authors. Licensee MDPI, Basel, Switzerland. This article is an open access article distributed under the terms and conditions of the Creative Commons Attribution (CC BY) license (http://creativecommons.org/licenses/by/4.0/). 